Working Paper 11-39-(10)

Business Economics Series

November 2011
Departamento de Economía de la Empresa

Universidad Carlos III de Madrid

Calle Madrid, 126

28903 Getafe (Spain)

Fax (34-91) 6249607

\title{
LICENSING RADICAL PRODUCT INNOVATIONS TO SPEED UP THE DIFFUSION*
}

\author{
Vardan Avagyan $^{1}$, Mercedes Esteban-Bravo ${ }^{2}$ and José M. Vidal-Sanz ${ }^{3}$
}

\begin{abstract}
Inventors can commercialize innovative products by themselves and simultaneously license the technology to other firms. The licensee may cannibalize sales of the licensor, but this can be compensated by gains from royalties. We show in this paper how licenses can be used strategically to speed up the new product diffusion process in two instances of markets: (i) a market with strong Intellectual Property Rights (IPR), and (ii) a market with weak IPR holder and pirate rivals. The main findings suggest that licensing is a beneficial strategy for a licensor in the context of strong IPR, because licensor benefits from the royalties, the advertising investment and positive word-of-mouth effects by licensees. We compare this result with a weak IPR context, where piracy speeds up the product diffusion but this does not compensate IPR holder for the sales loss effect who is willing to license to get some royalties. However, pirates do not generally find interesting the licensing agreement. We present a comparative statics analysis based on numerical simulation.
\end{abstract}

Keywords: Product diffusion models, Licensing, Optimal Control and Differential games.

\footnotetext{
* Research funded by two research projects, by the Comunidad de Madrid and the Spanish Government.

${ }^{1}$ Vardan Avagyan, Department of Business Administration, University Carlos III de Madrid, C/ Madrid 126, 28903 Getafe (Madrid), Spain; tel: +34 91624 8921; fax: +34 91624 8921; e-mail: vavagyan@emp.uc3m.es

${ }^{2}$ Mercedes Esteban-Bravo, Department of Business Administration, University Carlos III de Madrid, C/ Madrid 126, 28903 Getafe (Madrid), Spain; tel: +34 91624 8921; fax: +34 91624 8921; e-mail: mesteban@emp.uc3m.es

3 Jose M. Vidal-Sanz, Department of Business Administration, University Carlos III de Madrid, C/ Madrid 126, 28903 Getafe (Madrid), Spain; tel: +34 91624 8642; fax: +34 91624 9607; e-mail: jvidal@emp.uc3m.es
} 


\section{Introduction}

The diffusion of new products has drawn considerable attention in marketing literature for both radical product innovations (e.g., Bass 1969; Mahajan et al. 1990, 1993, Sultan et al. 1990, Chandrasekaran and Tellis 2007) and incremental product innovations as "new generations" (e.g., Norton and Bass 1987, Mahajan and Muller 1996). A variety of extensions have incorporated competitive marketing mix variables to control the diffusion process (e.g., Robinson and Lakhani 1975, Horsky and Simon 1983, Kalish 1985, Horsky and Mate 1988, Bass et al. 1994, 2000, Krishnan et al. 1999). The diffusion literature deals mainly with monopolies of category level growth, but there are some extensions for rival brands (e.g., Parker and Gatignon 1994, Bayus et al. 2000, Prasad and Mahajan 2003, Savin and Terwiesch 2005, Libai et al. 2009).

In most cases, the diffusion process has been modeled with first order differential equations where the solution is an "S" shape curve. After commercialization, the early diffusion of radical innovations is usually characterized by a slow growth that is eventually followed by a sharp increase known as sales "takeoff" (e.g., Mahajan et al. 1990, Rogers 1995, Golder and Tellis 1997, Klepper 1997). Diffusion takeoff time and speed are critical for the company, with deep implications over the supply-chain, inventory and product distribution management. It has also a crucial impact on firm value (an early takeoff increases the net present value of the innovation, as revenues cashed into the distant future are heavily discounted). The time to takeoff in the sales diffusion of radical product innovations can vary considerably (e.g., Mahajan et al. 1990, Golder and Tellis 1997). There are also demand cultural factors suggesting that sales takeoff can vary on different countries (Tellis, Stremersch and Yin 2003).

Over the last decade, there has been much interest in explaining the takeoff. The literature is mostly descriptive, and has established that marketing mix factors, particularly price-decreases and advertising effort, can partially explain the takeoff times (e.g., Stoneman and Ireland 1983, Golder and Tellis 1997, 2004, Foster et al. 2004). In addition, Agarwall and Bayus (2002) considered that the entry of new competitors during the early years of the market can push the demand outward, driven by improvements in product quality, distribution infrastructures, and higher awareness, suggesting that firm entrance may dominate the classical marketing-mix factors in explaining the takeoff times. For incremental innovations, there is also some evidence of cross-generation acceleration (Stremersch et al. 2010). Loosely speaking, the affluence of competing firms seems to spur higher innovation awareness through combined advertising and promotional efforts, price reductions due to firm rivalry, and product differentiation by quality improvements that (moderated by sociodemographic and environmental factors) can explain the first large increase in sales. But innovation ownership is usually protected by the Intellectual Property Rights (IPR) generating a temporal grant of monopoly power over the right to make commercial use of ideas. This protection may prevent the entrance of other firms, and therefore delay the takeoff time and/or decrease the diffusion speed.

This paper considers the use of licenses as a strategy to speed up the sales diffusion process of new products. Instead of commercializing the innovation alone, an inventing firm can license the product technology to one or more other firms. A license is a contract by which an IPR holder firm (licensor) transfers the right to exploit its innovation to another firm (licensee) under certain conditions and for a certain period of time. A number of studies have focused on studying optimal licensing contracts, providing conditions under which both parties find the license agreement convenient. Some work explicitly considers that licensing can increase the demand of new product through 
positive network externalities (Conner 1995) and improvements by quality competition (Shepard 1987). The theoretical industrial organization literature is mainly focused on static models (for a review see, e.g., Shapiro 1985 and Kamien 1992). In contrast to these papers, the current paper considers a sales diffusion process and looks at the benefits of licensing as a strategy to improve the licensor's profits by speeding up the sales diffusion through advertising and word-of-mouth effects of licensees. An analytical dynamic model is presented, featuring the Licensor-Licensee behavior as an open-loop Nash equilibrium in a differential game.

The strength of IPR laws can vary from some markets to others. Several studies have empirically considered the relationship between patent protection and licensing, finding that there is a higher propensity to license in industries with strong patent protection (e.g., Anand and Khanna 2000, Arora and Ceccagnoli 2006, Gambardella et al. 2007). However, there is little understanding of the positive effects of licensing to speed up the sales diffusion under different levels of IPR protection. This paper describes when licensing is profitable strategy for IPR holder in these two instances of markets: (i) a market with strong IPR, and (ii) a market with weak IPR and pirate rivals, who commercialize unlicensed product imitations.

The remainder of the paper is structured as follows. In the next section, we characterize optimal licensing, pricing and advertising strategies, and we analyze the sensitivity to the main parameters on the optimal profits using numerical methods, when IPR are strong. In section 3, we conduct similar analysis for the case when IPR are weak. Section 4 provides a simple empirical application of the licensing model to a case of electric bulb licensing in United Kingdom. Finally, the paper concludes with discussion and suggestions for future research.

\section{Licensing Radical Innovations in Markets with Strong IPR}

We consider a market of regularly purchased products. The diffusion of a radical innovation follows a Bass-type specification driven by additional marketing mix variables. Similar to Gupta et al. (2006), we consider that $\dot{N}_{t}$ is the net customer growth, $N_{t}$ are sales (instead of penetration in classical Bass model) generating returns $\left(p_{t}-c_{t}\right) N_{t}$, and there is a proportion $k \in(0,1)$ of defections and a potential level of customers $M>0$. Therefore, the customers' growth is given by

$$
\dot{N}_{t}=\left[\left(a+u \frac{N_{t}}{M}\right)\left(M-N_{t}\right)-k N_{t}\right] W_{t}\left(A_{t}, p_{t}\right), \quad N_{0}=0,
$$

where $W\left(A_{t}, p_{t}\right)$ conveys the impact of advertising expenditure $A_{t}$ and price $p_{t}$ on the growth of sales. Multiplicative marketing mix impact has been previously considered in the diffusion literature, particularly the model of Bass et al. (1994) recently criticized by Fruchter and Van den Bulte (2010) due to some theoretical problems. Similarly to Horsky and Simon (1983) model, in this paper we assume that advertising has a logarithmic impact on sales diffusion and the market potential. Also, we consider that the impact of prices depends on the deviation from an ideal-point price $\bar{p} \geq 0$, and this benchmark evolves according to an inflation rate $r \geq 0$ of consumption goods, so that the adoption process is faster when the distance $\left(e^{r t} \bar{p}-p_{t}\right)^{2}$ is small. Therefore we have specified the model

$$
W_{t}\left(A_{t}, p_{t}\right)=1+b \ln A_{t}-m\left(e^{r t} \bar{p}-p_{t}\right)^{2}
$$


and $a, b, m, u, M>0$. Note that this specification allows $\bar{p}=0$, so that $W\left(A_{t}, p_{t}\right)$ is monotonously decreasing with $p_{t}$. This is the case of some mass consumption products. For luxurious goods we would generally expect large values of $\bar{p}$.

Note that $W_{t}\left(A_{t}, p_{t}\right)=1$ when $A_{t}=1$ and the price equals to the ideal point $p_{t}=e^{r t} \bar{p}$. Then a stationary equilibrium is reached when $0=\left(a+u N^{*} / M\right)\left(M-N^{*}\right)-k N^{*}$. If $u=0$, with $a+k \neq 0$ the solution is $N^{*}=M a /(a+k)$ (which tends to $M$ when the defection parameter $k \downarrow 0$ decrease or $a \uparrow \infty)$. For the general case, when $u \neq 0$, the long-term solution is:

$$
N^{*}=M \frac{(u-a-k) \pm \sqrt{(u-a-k)^{2}+4 a u}}{2 u},
$$

which is smaller than the market potential. Obviously, when there are no defections, $k=0$, the long-term equilibrium reaches the market potential as $N^{*}=\frac{M}{2 u}\left((u-a)+\sqrt{(a+u)^{2}}\right)=M$.

Managing the marketing mix the companies can control the dynamics of the diffusion-defections balance.

We assume that the innovation is a variable-costs product with marginal cost $c_{t}=c_{0} e^{\pi t}$ where $c_{0}>0$, and $\pi$ can be negative, zero, or positive, depending on whether the cost dynamics is dominated by industrial inflation or learning effects, or both are balanced. Note that in most models $c_{t}=c_{0}$, and we will stress this case. Denote by $i>0$ the firm time-preference discount rate, that satisfies $i>\pi$ and $i>r$. The firm's present value of future profits is given by

$$
\Pi=\int_{0}^{\infty} e^{-i t}\left(\left(p_{t}-c_{t}\right) N_{t}-A_{t}\right) d t
$$

In a monopolistic setting the firm faces the problem of maximizing profit $\Pi$ subject to the diffusion equation (1).

\subsection{Strategic Analysis}

Denote by the letter $h$ the firm (licensor or IPR holder) that holds a license in a market with an IPR protection. The IPR holder would be willing to license its innovation, if the additional revenue from licensing is positive and the monopoly's profits could be never higher than those of oligopoly with competing licensees. Next we describe the two possible scenarios: a monopolistic strategy versus licensing strategy.

Strategy 1 Holding a monopolistic position in the market. The firm faces the problem of maximizing profit by choosing price and advertising effort:

$$
\begin{array}{|ll|}
\hline \max \Pi_{\text {mon }}^{h}\left(p_{t}^{h}, A_{t}^{h}, N_{t}^{h}\right)= & \int_{0}^{\infty} e^{-i t}\left(\left(p_{t}^{h}-c_{t}^{h}\right) N_{t}^{h}-A_{t}^{h}\right) d t \\
& \dot{N}_{t}^{h}=\left[\left(a+u \frac{N_{t}^{h}}{M}\right)\left(M-N_{t}^{h}\right)-k_{h} N_{t}^{h}\right] W_{t}\left(A_{t}^{h}, p_{t}^{h}\right), \\
& N_{0}^{h}=0,
\end{array}
$$


where $p^{h}$ is the product price and $A^{h}$ the marketing effort, $c_{t}^{h}$ are the unit costs, $e^{-i}$ the discount parameter. Denote by $\Pi_{m o n}^{h}$ the monopolist optimal value.

Alternatively, the firm can consider licensing its innovation. Then, the sales diffusion of the IPR holder is driven by

$$
\dot{N}_{t}^{h}=\left[\left(a+u \frac{N_{t}^{h}}{M}+g \frac{N_{t}^{l}}{M}\right)\left(M-N_{t}^{h}-N_{t}^{l}\right)-k_{h} N_{t}^{h}\right] W_{t}^{h}\left(A_{t}^{h}, A_{t}^{l}, p_{t}^{h}, p_{t}^{l}\right)
$$

with

$$
W_{t}^{h}\left(A_{t}^{h}, A_{t}^{l}, p_{t}^{h}, p_{t}^{l}\right)=1+b \ln A_{t}^{h}+s \ln A_{t}^{l}-m\left(e^{r t} \bar{p}-p_{t}^{h}\right)^{2}+d\left(e^{r t} \bar{p}-p_{t}^{l}\right)^{2}
$$

where $b, s, m, d>0$.

Also, the IPR holder charges to each licensee a royalty fee over sales $r_{t}^{h}$ and a fixed fee $f_{t}^{h}$. We consider a market potential of $L$ licensees. In order to make the problem tractable, we consider that all licensed companies are relatively homogenous with constant marginal cost $c_{t}^{l}$, selling at the same price $p_{t}^{l}$. Therefore, we consider the aggregated sales of all licensees on a single brand $l$, and we assume that $N_{t}^{l}$ are the sales of all licensees and $A_{t}^{l}$ is the total marketing effort. The growth rate $\dot{N}_{t}^{l}$ depends on the penetration of licensed companies $l_{t} / L$, defined as follows:

$$
\dot{N}_{t}^{l}=\left[\left(\alpha+v \frac{N_{t}^{h}}{M}+\gamma \frac{N_{t}^{l}}{M}+\chi \frac{l_{t}}{L}\right)\left(M-N_{t}^{h}-N_{t}^{l}\right)-k_{l} N_{t}^{l},\right] W_{t}^{l}\left(A_{t}^{h}, A_{t}^{l}, p_{t}^{h}, p_{t}^{l}\right)
$$

with

$$
W_{t}^{l}\left(A_{t}^{h}, A_{t}^{l}, p_{t}^{h}, p_{t}^{l}\right)=1+\beta \ln A_{t}^{h}+\sigma \ln A_{t}^{l}+\mu\left(e^{r t} \bar{p}-p_{t}^{h}\right)^{2}-\delta\left(e^{r t} \bar{p}-p_{t}^{l}\right)^{2}
$$

where $\beta, \sigma, \mu, \delta>0$.

The number of licensed firms, denoted by $l_{t}$, follows a Bass model in the following way:

$$
\dot{l}_{t}=\left[\left(z_{1}+z_{2} \frac{l_{t}}{L}+z_{3} \frac{N_{t}^{l}}{M}\right)\left(L-l_{t}\right)-z_{4} l_{t}\right] L_{t}\left(f_{t}^{h}, r_{t}^{h}\right)
$$

with

$$
L_{t}\left(f_{t}^{h}, r_{t}^{h}\right)=1-z_{5}\left(e^{r t} \bar{f}-f_{t}^{h}\right)^{2}-z_{6}\left(e^{r t} \bar{r}-r_{t}^{h}\right)^{2}
$$

where $z_{5}, z_{6}>0$. The adoption rate of the licensee companies $l_{t}$ depends on number of previously adopted companies, as well as on the market penetration level of licensees' sales. In most of the scenarios we assume that there is no deflection of licensees, i.e. $z_{4}=0$. Additionally, the adoption rate of the licensees is controlled by the license fees $f_{t}^{h}$ and $r_{t}^{h}$. 
The IPR firm $h$ and the licensee $l$ sell their brands at different prices, and each firm benefits from the rival advertising to lesser extent, similarly to the model adopted from Gupta et al. (2006), Libai et al. (2009) and Savin and Terwiesch (2005). We consider $W_{t}^{h}\left(A_{t}^{h}, A_{t}^{l}, p_{t}^{h}, p_{t}^{l}\right)$ and $W_{t}^{l}\left(A_{t}^{h}, A_{t}^{l}, p_{t}^{h}, p_{t}^{l}\right)$ with positive parameters, therefore for both players we assume that sales growth increases with the advertising of any firm $h$ and $l$, and sales growth decreases (increases) with an increase of own (competitors') price, i.e. $h$ and $l$ brands are substitutes. As firms generally address their advertising effort to their targeted segment by emphasizing their own product, and we assume that $b>s$ and $\sigma>\beta$; i.e., the effect of the own advertising in the sales is larger than the competitors' one. Similarly to Dockner and Jorgensen (1988), we assume that for price parameters $m>d, \delta>\mu$; i.e., the effect of the own price is larger than that of the competitors', which means that if all firms increase their prices, they will encounter a decrease in their sales growth.

Denote by $c_{t}^{h}, c_{t}^{l}$ the unit costs of the IPR holder and the licensee, respectively, which may be even identical if the production license covers all the know-how required for production. In this context, the following strategy is considered:

Strategy 2 Allowing a licensed substitute. Consider two substitutive brands (the patent holder $h$ and the licensee $l$ ). The licensing strategy is characterized by a dynamic Nash equilibrium as follows:

- LICENSEE: Given the decisions of the licensor $\left\{A_{t}^{h}, p_{t}^{h}, r_{t}^{h}, f_{t}^{h}\right\}$, the licensees solve the problem:

\begin{tabular}{ll|}
\hline $\max \Pi_{l i c}^{l}\left(p_{t}^{l}, A_{t}^{l}, N_{t}^{l}\right)=$ & $\int_{0}^{\infty} e^{-i t}\left(\left(p_{t}^{l}-c_{t}^{l}-r_{t}^{h}\right) N_{t}^{l}-A_{t}^{l}-f_{t}^{h} l_{t}\right) d t$ \\
s.t. & $(2),(3),(4)$ \\
\hline
\end{tabular}

and $N_{0}^{l}=0, N_{0}^{l}=0, l_{0}=0$.

- LICENSOR (IPR HOLDER): Given the decisions of the licensees $\left\{A_{t}^{l}, p_{t}^{l}\right\}$, the licensor solves the problem

\begin{tabular}{|ll|}
\hline $\max \Pi_{l i c}^{h}\left(r_{t}^{h}, f_{t}^{h}, p_{t}^{h}, A_{t}^{h}, N_{t}^{h}\right)=$ & $\int_{0}^{\infty} e^{-i t}\left(\left(p_{t}^{h}-c_{t}^{h}\right) N_{t}^{h}-A_{t}^{h}+f_{t}^{h} l_{t}+r_{t}^{h} N_{t}^{l}\right) d t$ \\
s.t. & $(2),(3),(4)$
\end{tabular}

and $N_{0}^{l}=0, N_{0}^{l}=0, l_{0}=0$.

- In the licensing scenario, we denote the optimal profits in an open-loop Nash equilibrium (for a definition see the Appendix) for licensor and licensee companies by $\Pi_{l i c}^{h}, \Pi_{l i c}^{l}$, respectively.

The dynamic Nash equilibrium is generally defined using two alternative approaches: the openloop Nash equilibrium and the closed-loop Nash equilibrium associated to different information structures. In an open-loop equilibrium, the decision of each agent satisfies the first order conditions of its maximization problem ceteris paribus the actions of the remainder players. By contrast, in a closed-loop Nash equilibrium it is assumed that each agent knows exactly how the other players will react to their decisions and anticipate these reactions in their first order conditions (see the appendix for a more formal description). Such managerial omniscience is generally unrealistic, but when it occurs the (closed-loop) equilibrium path is more robust to dynamic deviations, meaning that the closed-loop equilibrium is identified with a subgame-perfect equilibrium. In this paper we consider licensing solution with open-loop information structure. 


\subsection{Optimal Strategic Solution}

To determine whether the licensing strategy is implemented, we compute the optimal solution with and without licensing.

Licensing decision The decision to license is viable if and only if:

$$
\Pi_{l i c}^{h} \geq \Pi_{m o n}^{h}, \quad \Pi_{l i c}^{l} \geq 0 .
$$

To solve the viability of licensing for a particular parametrization of the model, we should compute the first order conditions for each firm, and study if the licensing conditions are verified. Next we provide the Hamilton-Jacobi-Bellman (HJB) first order conditions for the optimal policies based on Strategy 1 and Strategy 2. All the proofs can be found in the Appendix.

Proposition 1 The optimal pricing and advertising decisions for a monopolistic IPR holder (Strategy 1) are given by:

$$
\begin{aligned}
p_{t}^{h} & =\quad e^{r t} \bar{p}+\frac{e^{-i t} N_{t}^{h}}{\lambda_{t}^{h} 2 m\left[\left(a+u \frac{N_{t}^{h}}{M}\right)\left(M-N_{t}^{h}\right)-k_{h} N_{t}^{h}\right]}, \\
A_{t}^{h} & =b e^{i t} \lambda_{t}^{h}\left[\left(a+u \frac{N_{t}^{h}}{M}\right)\left(M-N_{t}^{h}\right)-k_{h} N_{t}^{h}\right],
\end{aligned}
$$

where $N_{t}^{h}, \lambda_{t}^{h}$ are the solution to the Boundary Value Problem (BVP) defined by

$$
\begin{aligned}
\dot{N}_{t}^{h}= & {\left[\left(a+u \frac{N_{t}^{h}}{M}\right)\left(M-N_{t}^{h}\right)-k_{h} N_{t}^{h}\right]\left(1+b \ln A_{t}^{h}-m\left(e^{r t} \bar{p}-p_{t}^{h}\right)^{2}\right) } \\
\dot{\lambda}_{t}^{h}=\quad-e^{-i t}\left(p_{t}^{h}-c_{t}^{h}\right) & \\
& -\lambda_{t}^{h}\left(\frac{u}{M}\left(M-N_{t}^{h}\right)-\left(a+u \frac{N_{t}^{h}}{M}\right)-k_{h}\right)\left(1+b \ln A_{t}^{h}-m\left(e^{i t} \bar{p}-p_{t}^{h}\right)^{2}\right)
\end{aligned}
$$

with $N_{0}^{h}=0, \lim _{t \rightarrow \infty} \lambda_{t}^{h} N_{t}^{h}=0$.

Proposition 2 The open-loop Nash equilibrium pricing and advertising decisions when the license (Strategy 2) is implemented, are given by:

$$
\begin{aligned}
p_{t}^{l}= & e^{r t} \bar{p}+e^{-i t} N_{t}^{l} /\left(-\lambda_{1 t}^{l} 2 d\left(\left(a+u \frac{N_{t}^{h}}{M}+g \frac{N_{t}^{l}}{M}\right)\left(M-N_{t}^{h}-N_{t}^{l}\right)-k_{h} N_{t}^{h}\right)\right. \\
& \left.+\lambda_{3 t}^{l} 2 \delta\left(\left(\alpha+v \frac{N_{t}^{h}}{M}+\gamma \frac{N_{t}^{l}}{M}+\chi \frac{l_{t}}{L}\right)\left(M-N_{t}^{h}-N_{t}^{l}\right)-k_{l} N_{t}^{l}\right)\right) \\
p_{t}^{h}= & e^{r t} \bar{p}+e^{-i t} N_{t}^{h} /\left(\lambda_{1 t}^{h} 2 m\left[\left(a+u \frac{N_{t}^{h}}{M}+g \frac{N_{t}^{l}}{M}\right)\left(M-N_{t}^{h}-N_{t}^{l}\right)-k_{h} N_{t}^{h}\right]\right. \\
- & \left.\lambda_{3 t}^{h} 2 \mu\left[\left(\alpha+v \frac{N_{t}^{h}}{M}+\gamma \frac{N_{t}^{l}}{M}+\chi \frac{l_{t}}{L}\right)\left(M-N_{t}^{h}-N_{t}^{l}\right)-k_{l} N_{t}^{l}\right]\right) \\
A_{t}^{l}= & e^{i t}\left[\lambda_{1 t}^{l} s\left(a+u \frac{N_{t}^{h}}{M}+g \frac{N_{t}^{l}}{M}\right)+\lambda_{3 t}^{l} \sigma\left(\alpha+v \frac{N_{t}^{h}}{M}+\gamma \frac{N_{t}^{l}}{M}+\chi \frac{l_{t}}{L}\right)\right] \\
& \times\left(M-N_{t}^{h}-N_{t}^{l}\right)-k_{h} s e^{i t} \lambda_{1 t}^{l} N_{t}^{h}-k_{l} \sigma e^{i t} \lambda_{3 t}^{l} N_{t}^{l} \\
A_{t}^{h}= & e^{i t}\left[b \lambda_{1 t}^{h}\left(a+u \frac{N_{t}^{h}}{M}+g \frac{N_{t}^{l}}{M}\right)+\lambda_{3 t}^{h} \beta\left(\alpha+v \frac{N_{t}^{h}}{M}+\gamma \frac{N_{t}^{l}}{M}+\chi \frac{l_{t}}{L}\right)\right] \\
& \times\left(M-N_{t}^{h}-N_{t}^{l}\right)-k_{h} b e^{i t} \lambda_{1 t}^{h} N_{t}^{h}-k_{l} \beta e^{i t} \lambda_{3 t}^{h} N_{t}^{l},
\end{aligned}
$$




$$
\begin{aligned}
& r_{t}^{h}=e^{r t} \bar{r}+\frac{e^{-i t} N_{t}^{l}}{\lambda_{2 t}^{h} 2 z_{6}\left[\left(z_{1}+z_{2} \frac{l_{t}}{L}+z_{3} \frac{N_{t}^{l}}{M}\right)\left(L-l_{t}\right)-z_{4} l_{t}\right]} \\
& f_{t}^{h}=e^{r t} \bar{f}+\frac{e^{-i t} l_{t}}{\lambda_{2 t}^{h} 2 z_{5}\left[\left(z_{1}+z_{2} \frac{l_{t}}{L}+z_{3} \frac{N_{t}^{l}}{M}\right)\left(L-l_{t}\right)-z_{4} l_{t}\right]}
\end{aligned}
$$

and the variables $N_{t}^{h}, N_{t}^{l}, l_{t}$, and $\lambda_{1 t}^{l}, \lambda_{2 t}^{l}, \lambda_{3 t}^{l}, \lambda_{1 t}^{h}, \lambda_{2 t}^{h}, \lambda_{3 t}^{h}$ are the solution to the BVP defined by equations (2), (3), (4), the co-state equations for the licensee

$$
\begin{aligned}
\dot{\lambda}_{1 t}^{l}= & -\lambda_{1 t}^{l}\left[u \frac{1}{M}\left(M-N_{t}^{h}-N_{t}^{l}\right)-\left(a+u \frac{N_{t}^{h}}{M}+g \frac{N_{t}^{l}}{M}\right)-k_{h}\right] W_{t}^{h}\left(A_{t}^{h}, A_{t}^{l}, p_{t}^{h}, p_{t}^{l}\right) \\
& -\lambda_{3 t}^{l}\left[\frac{v}{M}\left(M-N_{t}^{h}-N_{t}^{l}\right)-\left(\alpha+v \frac{N_{t}^{h}}{M}+\gamma \frac{N_{t}^{l}}{M}+\chi \frac{l_{t}}{L}\right)\right] W_{t}^{l}\left(A_{t}^{h}, A_{t}^{l}, p_{t}^{h}, p_{t}^{l}\right), \\
\dot{\lambda}_{2 t}^{l}= & e^{-i t} f_{t}-\lambda_{2 t}^{l}\left[\frac{z_{2}}{L}\left(L-l_{t}\right)-\left(z_{1}+z_{2} \frac{l_{t}}{L}+z_{3} \frac{N_{t}^{l}}{M}\right)-z_{4}\right] L_{t}\left(f_{t}^{h}, r_{t}^{h}\right) \\
& -\lambda_{3 t}^{l} \frac{\chi}{L}\left(M-N_{t}^{h}-N_{t}^{l}\right) W_{t}^{l}\left(A_{t}^{h}, A_{t}^{l}, p_{t}^{h}, p_{t}^{l}\right), \\
\dot{\lambda}_{3 t}^{l}= & -e^{-i t}\left(p_{t}^{l}-c_{t}^{l}-r_{t}^{h}\right) \\
& -\lambda_{1 t}^{l}\left(g \frac{1}{M}\left(M-N_{t}^{h}-N_{t}^{l}\right)-\left(a+u \frac{N_{t}^{h}}{M}+g \frac{N_{t}^{l}}{M}\right)\right) W_{t}^{h}\left(A_{t}^{h}, A_{t}^{l}, p_{t}^{h}, p_{t}^{l}\right) \\
& -\lambda_{2 t}^{l} \frac{z_{3}}{M}\left(L-l_{t}\right) L_{t}\left(f_{t}^{h}, r_{t}^{h}\right) \\
& -\lambda_{3 t}^{l}\left(\frac{\gamma}{M}\left(M-N_{t}^{h}-N_{t}^{l}\right)-\left(\alpha+v \frac{N_{t}^{h}}{M}+\gamma \frac{N_{t}^{l}}{M}+\chi \frac{l_{t}}{L}\right)-k_{l}\right) W_{t}^{l}\left(A_{t}^{h}, A_{t}^{l}, p_{t}^{h}, p_{t}^{l}\right),
\end{aligned}
$$

and the co-state equations for the IPR holder

$$
\begin{aligned}
\dot{\lambda}_{1 t}^{h}= & -e^{-i t}\left(p_{t}^{h}-c_{t}^{h}\right) \\
& -\lambda_{1 t}^{h}\left(\left[\frac{u}{M}\left(M-N_{t}^{h}-N_{t}^{l}\right)-\left(a+u \frac{N_{t}^{h}}{M}+g \frac{N_{t}^{l}}{M}\right)-k_{h}\right] W_{t}^{h}\left(A_{t}^{h}, A_{t}^{l}, p_{t}^{h}, p_{t}^{l}\right)\right) \\
& -\lambda_{3 t}^{h}\left[\frac{v}{M}\left(M-N_{t}^{h}-N_{t}^{l}\right)-\left(\alpha+v \frac{N_{t}^{h}}{M}+\gamma \frac{N_{t}^{l}}{M}+\chi \frac{l_{t}}{L}\right)\right] W_{t}^{l}\left(A_{t}^{h}, A_{t}^{l}, p_{t}^{h}, p_{t}^{l}\right), \\
\dot{\lambda}_{2 t}^{h}= & -e^{-i t} f_{t}^{h} \\
& -\lambda_{2 t}^{h}\left(\frac{z_{2}}{L}\left(L-l_{t}\right)-\left(z_{1}+z_{2} \frac{l_{t}}{L}+z_{3} \frac{N_{t}^{l}}{M}\right)-z_{4}\right) L_{t}\left(f_{t}^{h}, r_{t}^{h}\right) \\
& -\lambda_{3 t}^{h} \frac{\chi}{L}\left(M-N_{t}^{h}-N_{t}^{l}\right) W_{t}^{l}\left(A_{t}^{h}, A_{t}^{l}, p_{t}^{h}, p_{t}^{l}\right), \\
\dot{\lambda}_{3 t}^{h}= & -e^{-i t} r_{t}^{h} \\
& -\lambda_{1 t}^{h}\left(\left(\frac{g}{M}\left(M-N_{t}^{h}-N_{t}^{l}\right)-\left(a+u \frac{N_{t}^{h}}{M}+g \frac{N_{t}^{l}}{M}\right)\right) W_{t}^{h}\left(A_{t}^{h}, A_{t}^{l}, p_{t}^{h}, p_{t}^{l}\right)\right) \\
& -\lambda_{2 t}^{h} \frac{z_{3}}{M}\left(L-l_{t}\right) L_{t}\left(f_{t}^{h}, r_{t}^{h}\right) \\
& -\lambda_{3 t}^{h}\left[\frac{\gamma}{M}\left(M-N_{t}^{h}-N_{t}^{l}\right)-\left(\alpha+v \frac{N_{t}^{h}}{M}+\gamma \frac{N_{t}^{l}}{M}+\chi \frac{l_{t}}{L}\right)-k_{l}\right] W_{t}^{l}\left(A_{t}^{h}, A_{t}^{l}, p_{t}^{h}, p_{t}^{l}\right),
\end{aligned}
$$

with initial values $N_{0}^{h}=N_{0}^{l}=l_{0}=0$, and terminal conditions $\lim _{t \rightarrow \infty} \lambda_{1 t}^{l} N_{t}^{h}=0, \lim _{t \rightarrow \infty} \lambda_{2 t}^{l} l_{t}=$ $0, \lim _{t \rightarrow \infty} \lambda_{3 t}^{l} N_{t}^{l}=0, \lim _{t \rightarrow \infty} \lambda_{1 t}^{h} N_{t}^{h}=0, \lim _{t \rightarrow \infty} \lambda_{2 t}^{h} l_{t}=0, \lim _{t \rightarrow \infty} \lambda_{3 t}^{h} N_{t}^{l}=0$.

In order to discuss the optimality of the monopolistic approach (Strategy 1) compared with the licensing decision (Strategy 2) for the IPR holder, we should solve the optimal control systems substituting the optimal control expression in the associated BVP. The solution can be computed numerically with a Galerkin-Collocation method (for an introduction, see e.g. Judd 1998) 


\section{$2.3 \quad$ Numerical results}

Next we compute the optimal policies based on Strategy 1 and Strategy 2 for a set of parameters. As a base case, we assume an arbitrary total market size of 4000 units. We use coefficients of innovation of $a=0.002$ for the licensor sales, $\alpha=0.002$ for the licensee sales and the coefficients of imitation of $u=0.2 ; g=0.2$ for the licensor sales, and $v=0.2 ; \gamma=0.2 ; \chi=0.02$ for the licensee sales. We assume that the market of potential licensees is $L=90$, with a coefficient of innovation $z_{1}=2$, a coefficient of imitation of $z_{2}=0.5$ and a coefficient of imitation for the licensees $z_{3}=5$. The deflection rates for the three populations are set to 0 . We also assume that the variable cost is equal to $c_{0}=20$ both for the licensor and licensees (and $\pi=0$ ). We consider that the ideal-point of prices, royalty fees and fixed fees are $\bar{p}=100 ; \bar{f}=1200 ; \bar{r}=10$; and this benchmark evolves according to an inflation rate $r=0.07$. The sensitivity to the deviations from these ideal-points are set to $m=0.0007, d=0.0002$ for the licensor sales; $\mu=0.0002, \delta=0.0007$ for the licensees sales; and $z_{5}=0.0000015 ; z_{6}=0.00015$ for the licensees population. The efficiency of the advertising is set to $b=0.01 ; s=0.005$ for the licensor; and $\beta=0.005 ; \sigma=0.01$ for the licensees. We assume a discount rate of $i=0.1$.

For this set of parameters, the optimal profit for monopolist is $\Pi_{m o n}^{h}=9.6860 \cdot 10^{6}$; and the optimal profits of the licensor and the licensee are $\Pi_{l i c}^{h}=1.0620 \cdot 10^{7}$ and $\Pi_{l i c}^{l}=6.3513 \cdot 10^{5}$, respectively. The results are not surprising. The value of licensing is

$$
\Delta=\left(\Pi_{l i c}^{h}-\Pi_{m o n}^{h}\right)=9.34 \cdot 10^{5} .
$$

Indeed, there is a clear incentive for the IPR holder to license the innovation, because licensees pay for royalty fees. Actually, the discounted licensing revenue is about $50 \%$ of the total profit of the licensor (decreasing from an initial $90 \%$ down to around 40\%). Figure 1 shows that the discounted profits of the IPR holder growth rapidly to a maximum, and then decay exponentially. But for the lincensing strategy a higher value is achieved at a faster rate. The discounted profits of the licensee are smaller, but in the long term decay quite slowly.
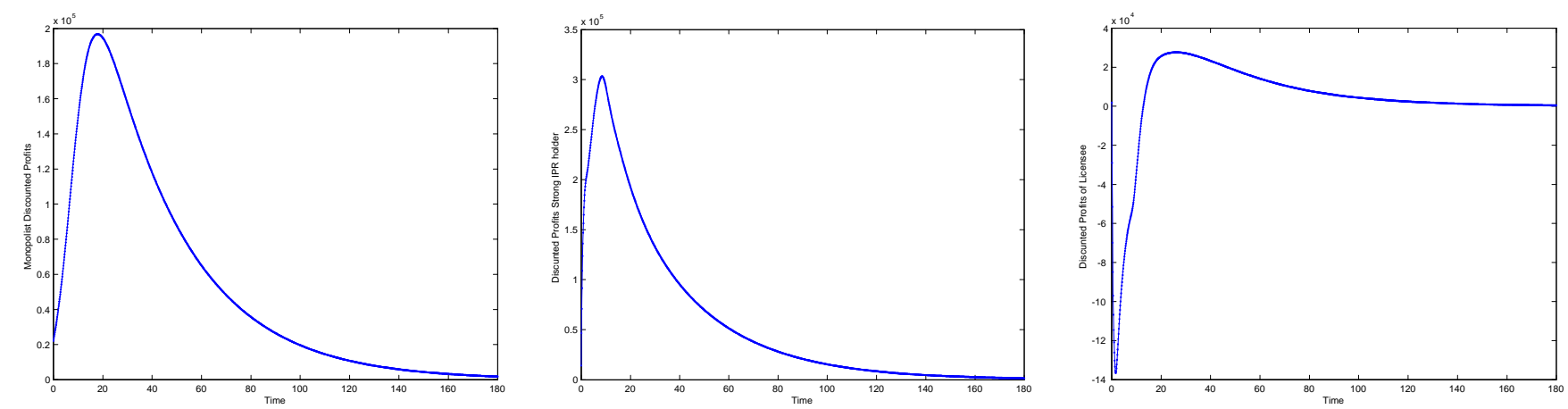

Figure 1: Discounted optimal profits of the Monopolist, Strong IPR holder and Licensee, respectively

Figure 2 depicts how the sales diffusion is accelerated when the licensing strategy is implemented. Initially, the IPR holder has more sales when being a licensor than in a monopolistic position. 
The IPR holder implicitly also benefits from the advertising efforts and the cross word-of-mouth influence of the licensees, which leads to faster diffusion and, as a result, more sales per period. Besides, it also gains licensing revenues. For the IPR holder, applying the monopolistic strategy provides, after some point of time, a higher level of sales than those obtain if the licensing strategy is implemented. However, aggregated licensor and licensee sales dominate the monopolist sales.

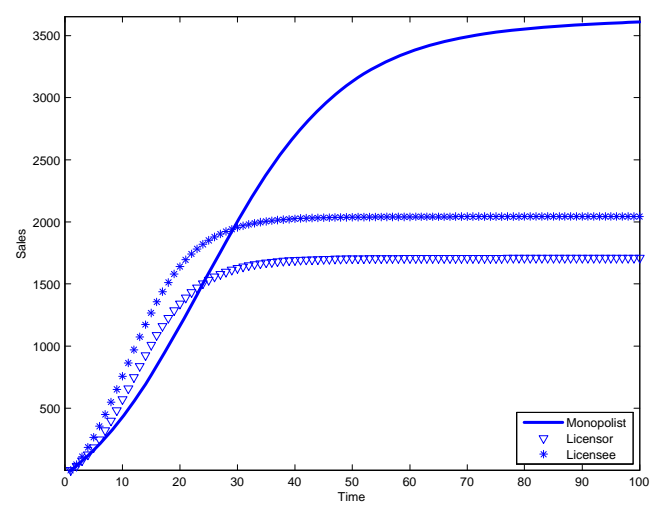

Figure 2: Sales diffusion in the context of strong IPR.

Discounted optimal prices decay and discounted optimal marketing effort investments decay exponentially for all the agents (see Figure 3). 

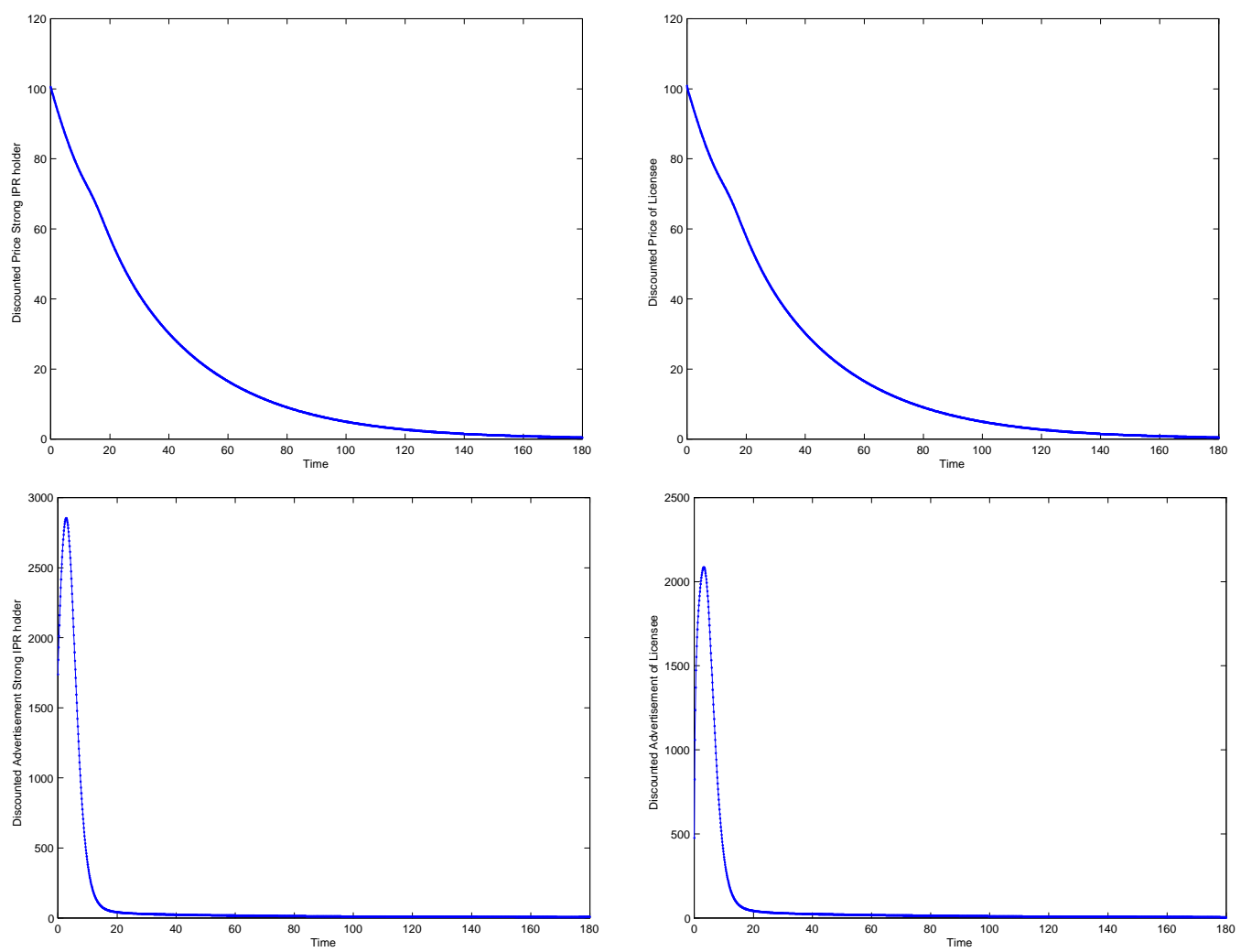

Figure 3. Optimal Discounted Prices and marketing effort under licensing.

Figure 4 depicts the discounted licensing payments, both royalties and fixed fees. They decay exponentially as the market becomes mature.
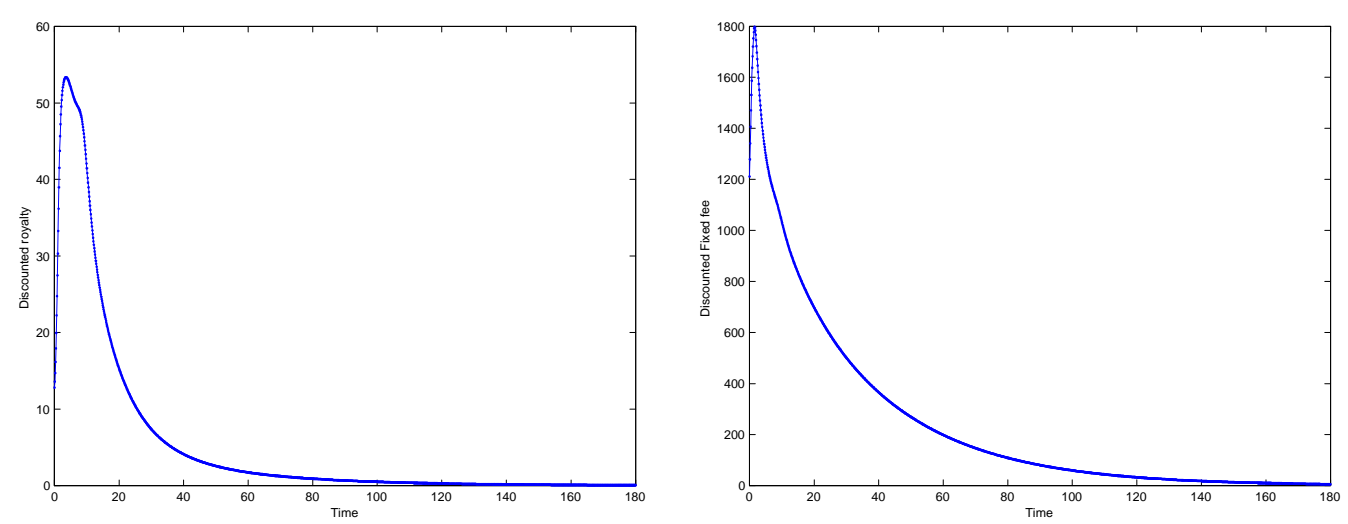

Figure 4. Discounted Licensing Payments 


\subsection{Comparative statics}

To get in-depth insights on the impact of the licensees, we provide a sensitivity analysis of the model's parameters. Consider all the parameters on a vector $\theta$. Using envelope theorem for differential games, we compute how "sensitive" the cumulative profits $\Pi_{m o n}^{h}, \Pi_{l i c}^{h}, \Pi_{l i c}^{l}$ are to changes in the value of the parameters in case of Strategy 1 and Strategy 2, respectively, and the partial derivatives $\partial \Delta\left(\theta_{0}\right) / \partial \theta$ (see the Appendix for analytical details about the envelope theorem; the partial derivatives with respect to each model parameter are available from authors). These expressions involve some integrals that cannot be solved analytically, and Table 1 reports the numerical values of the sensitivity analysis.

Table 1: Comparative statics for licensing and monopolistic strategies in strong IPR framework

\begin{tabular}{c||c|c|c|c|}
\hline$\theta$ & $\frac{\partial}{\partial \theta} \Pi_{l i c}^{h}\left(\cdot 10^{8}\right)$ & $\frac{\partial}{\partial \theta} \Pi_{l i c}^{l}\left(\cdot 10^{8}\right)$ & $\frac{\partial}{\partial \theta} \Pi_{\text {mon }}^{h}\left(\cdot 10^{8}\right)$ & $\frac{\partial \Delta}{\partial \theta}\left(\cdot 10^{8}\right)$ \\
\hline \hline$a$ & 0.4661 & -0.3264 & 0.4681 & -0.002 \\
\hline$u$ & 0.0746 & -0.0616 & 0.1196 & -0.045 \\
\hline$M$ & 0.000022 & 0.0000049 & 0.000027 & -0.000005 \\
\hline$m$ & -0.5842 & -0.6066 & -1.3098 & 0.7256 \\
\hline $\bar{p}$ & 0.00052 & 0.0006 & 0.00098 & -0.00046 \\
\hline$b$ & 0.2521 & -0.2131 & 0.1887 & 0.0634 \\
\hline$k_{h}$ & -2.0407 & 2.0308 & -0.6618 & -1.3789 \\
\hline$i$ & -3.834 & -0.7721 & -4.0179 & 0.1839 \\
\hline$r$ & 3.3085 & 0.9313 & 4.0380 & -0.7295 \\
\hline$s$ & 0.2506 & -0.1937 & 0 & 0.2506 \\
\hline$d$ & -0.4060 & -0.6755 & 0 & -0.4060 \\
\hline$g$ & 0.0915 & -0.0754 & 0 & 0.0915 \\
\hline
\end{tabular}

\begin{tabular}{c||c|c|c|c|}
\hline$\theta$ & $\frac{\partial}{\partial \theta} \Pi_{l i c}^{h}\left(\cdot 10^{8}\right)$ & $\frac{\partial}{\partial \theta} \Pi_{\text {lic }}^{l}\left(\cdot 10^{8}\right)$ & $\frac{\partial}{\partial \theta} \Pi_{\text {mon }}^{h}$ & $\frac{\partial \Delta}{\partial \theta}\left(\cdot 10^{8}\right)$ \\
\hline \hline$\alpha$ & -0.1468 & 0.3205 & 0 & -0.1468 \\
\hline$v$ & -0.0400 & 0.0593 & 0 & -0.0400 \\
\hline$\gamma$ & -0.0489 & 0.0726 & 0 & -0.0489 \\
\hline$\mu$ & -0.4803 & -0.3269 & 0 & -0.4803 \\
\hline$\delta$ & -0.7131 & -0.7767 & 0 & -0.7131 \\
\hline$\beta$ & -0.1473 & 0.2510 & 0 & -0.1473 \\
\hline$\sigma$ & -0.1497 & 0.2350 & 0 & -0.1497 \\
\hline$k_{l}$ & 1.9515 & -2.2347 & 0 & 1.9515 \\
\hline$\chi$ & -0.1407 & 0.2770 & 0 & -0.1407 \\
\hline
\end{tabular}




\begin{tabular}{c||c|c|c|c|}
\hline$\theta$ & $\frac{\partial}{\partial \theta} \Pi_{\text {lic }}^{h}\left(\cdot 10^{8}\right)$ & $\frac{\partial}{\partial \theta} \Pi_{\text {lic }}^{l}\left(\cdot 10^{8}\right)$ & $\frac{\partial}{\partial \theta} \Pi_{\text {mon }}^{h}$ & $\frac{\partial \Delta}{\partial \theta}\left(\cdot 10^{8}\right)$ \\
\hline \hline$z_{1}$ & 0.00024 & 0.000069 & 0 & 0.00024 \\
\hline$z_{2}$ & 0.000088 & 0.000063 & 0 & 0.000088 \\
\hline$z_{3}$ & 0.0000001 & -0.00004 & 0 & 0.0000001 \\
\hline$z_{4}$ & -0.0064 & 0.0093 & 0 & -0.0064 \\
\hline$z_{5}$ & -1177.53 & 1316.51 & 0 & -1177.53 \\
\hline$z_{6}$ & -36.39 & 37.54 & 0 & -36.35 \\
\hline $\bar{r}$ & 0.00062 & -0.00062 & 0 & 0.00062 \\
\hline$f$ & 0.00002 & -0.00002 & 0 & 0.00002 \\
\hline$L$ & 0.0004 & -0.0006 & 0 & 0.0004 \\
\hline
\end{tabular}

The results are not surprising. We found negative values of $\partial \Delta / \partial a$ and $\partial \Delta / \partial u$ implying that the higher the innovation and word-of-mouth parameters are, the less the IPR holder is willing to license. When both $a$ and $u$ are large, product sales take off rapidly and the advantage of licensing to speed up the rate of diffusion of the innovation is not so clear. In addition, we found positive values of $\partial \Delta / \partial b, \partial \Delta / \partial s$ and $\partial \Delta / \partial g$ implying that the higher the impact of direct (or cross) advertising and the word-of-mouth on the licensor's sales growth, the more desirable the licensing strategy is.

An increase of licensor's price sensitivity $m$ implies that licensing is more interesting since the monopoly profits are reduced more than those of licensing scenario. However, an increase of licensees price impact $d$ make licensing strategy less desirable for the IPR holder. We also found a negative value of $\partial \Delta / \partial \bar{p}$, indicating that for products with higher desired price level the IPR holder rather prefers to be in a monopolistic position, than to share the market with licensee companies. Furthermore, the faster the desired price level evolves (higher inflation rate $r$ ), the more a monopolistic position is preferred.

Interestingly, it does not appear to be worthwhile licensing with an increase of the IPR holder's deflection rate $k_{h}$, as the negative impact of higher deflection rate on monopoly profit is smaller than on licensor profit. Importantly, discounting parameter increments do improve the value of licensing as a takeoff anticipation becomes crucial. In other words, the more a firm is impatient to be rewarded for its innovation, the more an IPR holder is willing to license.

There is no a straightforward relationship between market potential $M$ and licensing strategy. Computing the solution with different parameters, we found out that when cross advertising effects are moderate-to-large (higher than 0.005), then the higher market potential the more desirable a licensing strategy is. By contrast, when the cross advertising effects are smaller than 0.005 , then the higher the market potential the less desirable a licensing strategy is. This strengthen the idea that companies may consider both, cross-benefits of advertising and the size of the market as structural elements to consider before a decision is made.

As it comes to the parameters related to the licensee sales growth, the parametric changes which speed up the licensee sales (higher $a, \beta, \gamma, v, \chi, \sigma$, and lower $k_{l}$ ) make licensing strategy less desirable. Intuitively, faster licensee sales imply that the IPR holder receives more royalty revenues earlier. However, it also implies that the licensees capture the market faster, leaving the IPR holder with less sales revenues. 
Moreover, a higher licensee market potential $L$, larger $z_{1}, z_{2}, z_{3}$, and smaller $z_{4}, z_{5}, z_{6}$ (speeding up of licensee companies diffusion and reducing the sensitivity to fees), make licensing a more attractive strategy. This is because if the IPR holder chooses the licensing strategy, he would prefer that the licensees "diffuse" faster so that he gets licensing fees earlier. These results are relatively stable, although we have noticed that for high levels of production costs $\partial \Pi_{l i c}^{h} / \partial z_{3}$ becomes small and negative, but if cross advertising effects is simultaneously set to 0.003 the effect is again positive.

It is important to note that most of the parametric changes that make licensing contract more attractive for the licensor decrease the total profits earned by the licensees. However, as long as the licensees get positive profits, licensing is an attractive strategy for the licensees, as the licensees would get zero profits by not accepting the licensing contract.

\section{The case of weak IPR markets}

Product licensing decisions should be reconsidered when unlicensed pirate imitations can be "commercialized". The IPR holder faces a weak type of competition from a substitutive product with worse characteristics. But piracy also speeds up the product diffusion, bringing some issues that were not present in monopoly. In this context it is not so crucial to allow rival pirates to use legal licenses given that the license must be cheap enough to engage them into the legal binding.

\subsection{Strategic Model}

In the weak IPR context, we can study the sales of three possible products: (1) the IPR holder sales $N_{t}^{h} ;(2)$ the sales of copies produced by the firms without IPR $N_{t}^{c}$; and (3) the sales of licensed product $N_{t}^{l}$ if a license agreement is signed. We consider that only products (1) and (2), or products (1) and (3) are simultaneously observed in the market. We say that firms that only commercialize products of type (2) follow a pirating strategy. Often, the quality of the original and copied product is usually different, and therefore the competitiveness of IPR holder firm and pirates is weaker than in the case studied in Section 2. Therefore, we relaxed the assumption of a joint potential and assumed that brands can develop independently, with a market potential of $M^{h}$ for products of type (1) and $M^{c}$ for products of type (2), so that $M=M^{h}+M^{c}$, and separated diffusions (similarly to Parker and Gatignon, 1994, and Gupta et al., 2006)).

The sales of pirate products $N_{t}^{c}$ depend on the number of pirates $l_{t}^{c}$, and the dynamics of both variables are cross-related. Therefore, if the licensee is not granted, the diffusion of the innovative and pirate products and pirate companies are described by the following equations:

$$
\begin{aligned}
& \dot{N}_{t}^{h}=\left[\left(a+u \frac{N_{t}^{h}}{M^{h}}+g \frac{N_{t}^{c}}{M^{c}}\right)\left(M^{h}-N_{t}^{h}\right)-k_{h} N_{t}^{h}\right] W_{t}^{h}\left(A_{t}^{h}, A_{t}^{c}, p_{t}^{h}, p_{t}^{c}\right) \\
& W_{t}^{h}\left(A_{t}^{h}, A_{t}^{c}, p_{t}^{h}, p_{t}^{c}\right)=1+b \ln A_{t}^{h}+s \ln A_{t}^{c}-m\left(e^{r t} \bar{p}-p_{t}^{h}\right)^{2}+d\left(e^{r t} \overline{p^{c}}-p_{t}^{c}\right)^{2} \\
& \dot{N}_{t}^{c}=\left[\left(\alpha+v \frac{N_{t}^{h}}{M^{h}}+\gamma \frac{N_{t}^{c}}{M^{c}}+\chi \frac{l_{t}^{c}}{L}\right)\left(M^{c}-N_{t}^{c}\right)-k_{c} N_{t}^{c}\right] W_{t}^{c}\left(A_{t}^{h}, A_{t}^{c}, p_{t}^{h}, p_{t}^{c}\right) \\
& W_{t}^{c}\left(A_{t}^{h}, A_{t}^{c}, p_{t}^{h}, p_{t}^{c}\right)=1+\beta \ln A_{t}^{h}+\sigma \ln A_{t}^{c}-\delta\left(e^{r t} \overline{p^{c}}-p_{t}^{c}\right)^{2}+\mu\left(e^{r t} \bar{p}-p_{t}^{h}\right)^{2}
\end{aligned}
$$


and

$$
i_{t}^{c}=\left[\left(z_{1}+z_{2} \frac{l_{t}^{c}}{L}+z_{3} \frac{N_{t}^{c}}{M^{c}}\right)\left(L-l_{t}^{c}\right)-z_{4} l_{t}^{c}\right]
$$

By contrast, we assume that in licensing scenario products have relatively homogeneous quality, and therefore the demand structure is entirely analogous to model (2), (3), (4), with market potential $M=M^{h}+M^{c}$, and the sales are distributed among both firms accordingly to this model.

Typically the diffusion parameters of the IPR firm product $N_{t}^{h}$ and the licensed product $N_{t}^{l}$ are higher than in the copy $N_{t}^{c}$, due to higher quality of the innovation that increases the market potential and the speed of the diffusion (i.e., $a>\alpha, u>v, g>\gamma$ ), also $b>\sigma ; s>\beta$.

The licensor considers two possible scenarios: competition with pirating strategy versus licensing strategy (Strategy 2) with $M=M^{h}+M^{c}$.

Strategy 3 Unlicensing benchmark scenario with piracy. The equilibrium is characterized by the dynamic Nash equilibrium as follows:

- Given the decisions of the IPR holder $\left\{A_{t}^{h}, p_{t}^{h}\right\}$ the pirates, solve

$$
\begin{array}{|ll|}
\hline \max \Pi_{\text {piracy }}^{c}\left(p_{t}^{c}, A_{t}^{c}, N_{t}^{c}\right)= & \int_{0}^{\infty} e^{-i t}\left(\left(p_{t}^{c}-c_{t}^{c}\right) N_{t}^{c}-A_{t}^{c}\right) d t \\
\text { s.t. } & \text { eq. }(8),(9),(10) \\
\hline
\end{array}
$$

with $N_{0}^{c}=0, N_{0}^{h}=0$.

- Given the decisions of the pirates $\left\{A_{t}^{c}, p_{t}^{c}\right\}$, the IPR holder solves the problem

$$
\begin{array}{ll|}
\hline \max \Pi_{\text {piracy }}^{h}\left(p_{t}^{h}, A_{t}^{h}, N_{t}^{h}\right)= & \int_{0}^{\infty} e^{-i t}\left(\left(p_{t}^{h}-c_{t}^{h}\right) N_{t}^{h}-A_{t}^{h}\right) d t \\
\text { s.t. } & \text { eq. }(8),(9),(10) \\
\hline
\end{array}
$$

with $N_{0}^{c}=0, N_{0}^{h}=0$.

- Under piracy, we denote the optimal profits of IPR holder and pirates $\Pi_{\text {piracy }}^{h}$ and $\Pi_{\text {piracy }}^{c}$, respectively obtained in the open-loop Nash equilibrium.

Alternatively, a licensing agreement can be signed, and therefore, the IPR holder and the licensee follow Strategy 2 defined in Section 2, rendering profits $\Pi_{l i c}^{h}, \Pi_{l i c}^{l}$.

\subsection{Optimal Strategic Solution}

To determine whether the licensing strategy is implemented, consider the following decision rule:

Licensing decision The license decision is a viable equilibrium if and only if two conditions holds:

i) The IPR licensor gets higher profits with licensing than without licensing; i.e.,

$$
\Pi_{\text {lic }}^{h} \geq \Pi_{\text {piracy }}^{h}
$$


ii) The licensee obtains higher profits commercializing licensed products than unlicensed substitutes; i.e.,

$$
\Pi_{\text {lic }}^{l} \geq \Pi_{\text {piracy }}^{c}
$$

Next, we provide the first order conditions for the optimal policies under piracy, based on Strategy 3 .

Proposition 3 If an IPR holder faces piracy competition (Strategy 3), the open-loop Nash equilibrium pricing and advertising decisions are given by:

$$
\begin{aligned}
p_{t}^{c}= & e^{r t} \bar{p}^{c}+e^{-i t} N_{t}^{c} /\left(-\lambda_{1 t}^{c} 2 d\left[\left(a+u \frac{N_{t}^{h}}{M^{h}}+g \frac{N_{t}^{c}}{M^{c}}\right)\left(M^{h}-N_{t}^{h}\right)-k_{h} N_{t}^{h}\right]\right. \\
& \left.+\lambda_{3 t}^{c} 2 \delta\left[\left(\alpha+v \frac{N_{t}^{h}}{M^{h}}+\gamma \frac{N_{t}^{c}}{M^{c}}+\chi \frac{l_{t}^{c}}{L}\right)\left(M^{c}-N_{t}^{c}\right)-k_{c} N_{t}^{c}\right]\right), \\
p_{t}^{h}= & e^{r t} \bar{p}+e^{-i t} N_{t}^{h} /\left(\lambda_{1}^{h} 2 m\left[\left(a+u \frac{N_{t}^{h}}{M^{h}}+g \frac{N_{t}^{c}}{M^{c}}\right)\left(M^{h}-N_{t}^{h}\right)-k_{h} N_{t}^{h}\right]\right. \\
& \left.-\lambda_{3 t}^{h} 2 \mu\left[\left(\alpha+v \frac{N_{t}^{h}}{M^{h}}+\gamma \frac{N_{t}^{c}}{M^{c}}+\chi \frac{l_{t}^{c}}{L}\right)\left(M^{c}-N_{t}^{c}\right)-k_{c} N_{t}^{c}\right]\right), \\
A_{t}^{c}= & s \lambda_{1 t}^{c} e^{i t}\left[\left(a+u \frac{N_{t}^{h}}{M^{h}}+g \frac{N_{t}^{c}}{M^{c}}\right)\left(M^{h}-N_{t}^{h}\right)-k_{h} N_{t}^{h}\right] \\
& +\sigma \lambda_{3 t}^{c} e^{i t}\left[\left(\alpha+v \frac{N_{t}^{h}}{M^{h}}+\gamma \frac{N_{t}^{c}}{M^{c}}+\chi \frac{l_{t}^{c}}{L}\right)\left(M^{c}-N_{t}^{c}\right)-k_{c} N_{t}^{c}\right], \\
A_{t}^{h}= & b \lambda_{1 t}^{h} e^{i t}\left[\left(a+u \frac{N_{t}^{h}}{M^{h}}+g \frac{N_{t}^{c}}{M^{c}}\right)\left(M^{h}-N_{t}^{h}\right)-k_{h} N_{t}^{h}\right] \\
& +\beta \lambda_{3 t}^{h} e^{i t}\left[\left(\alpha+v \frac{N_{t}^{h}}{M^{h}}+\gamma \frac{N_{t}^{c}}{M^{c}}+\chi \frac{l_{t}^{c}}{L}\right)\left(M^{c}-N_{t}^{c}\right)-k_{c} N_{t}^{c}\right] .
\end{aligned}
$$

where $N_{t}^{h}, N_{t}^{c}, l_{t}^{c}, \lambda_{1 t}^{h}, \lambda_{2 t}^{h}, \lambda_{3 t}^{h}, \lambda_{1 t}^{c}, \lambda_{2 t}^{c}, \lambda_{3 t}^{c}$ are the solution to the BVP defined by (8), (9), and the respective co-state equations

$$
\begin{aligned}
\dot{\lambda}_{1 t}^{c}= & -\lambda_{1 t}^{c}\left[u \frac{1}{M^{h}}\left(M^{h}-N_{t}^{h}\right)-\left(a+u \frac{N_{t}^{h}}{M^{h}}+g \frac{N_{t}^{c}}{M^{c}}\right)-k_{h}\right] W_{t}^{h}\left(A_{t}^{h}, A_{t}^{c}, p_{t}^{h}, p_{t}^{c}\right) \\
& -\lambda_{3 t}^{c} v \frac{1}{M^{h}}\left(M^{c}-N_{t}^{c}\right) W_{t}^{c}\left(A_{t}^{h}, A_{t}^{c}, p_{t}^{h}, p_{t}^{c}\right) \\
\dot{\lambda}_{2 t}^{c}= & -\lambda_{2 t}^{c}\left[z_{2} \frac{1}{L}\left(L-l_{t}^{c}\right)-\left(z_{1}+z_{2} \frac{l_{t}^{c}}{L}+z_{3} \frac{N_{t}^{c}}{M^{c}}\right)\left(L-l_{t}^{c}\right)-z_{4}\right] \\
& -\lambda_{3 t}^{c} \chi \frac{1}{L}\left(M^{c}-N_{t}^{c}\right) W_{t}^{c}\left(A_{t}^{h}, A_{t}^{c}, p_{t}^{h}, p_{t}^{c}\right), \\
\dot{\lambda}_{3 t}^{c}= & -e^{-i t}\left(p_{t}^{c}-c_{t}^{c}\right)-\lambda_{1 t}^{c} g \frac{1}{M^{c}}\left(M^{h}-N_{t}^{h}\right) W_{t}^{h}\left(A_{t}^{h}, A_{t}^{c}, p_{t}^{h}, p_{t}^{c}\right)-\lambda_{2 t}^{c} z_{3} \frac{1}{M^{c}}\left(L-l_{t}^{c}\right) \\
& -\lambda_{3 t}^{c}\left[\gamma \frac{1}{M^{c}}\left(M^{c}-N_{t}^{c}\right)-\left(\alpha+v \frac{N_{t}^{h}}{M^{h}}+\gamma \frac{N_{t}^{c}}{M^{c}}+\chi \frac{l_{t}^{c}}{L}\right)-k_{c}\right] W_{t}^{c}\left(A_{t}^{h}, A_{t}^{c}, p_{t}^{h}, p_{t}^{c}\right)
\end{aligned}
$$

and

$$
\begin{aligned}
\dot{\lambda}_{1 t}^{h}= & -e^{-i t}\left(p_{t}^{h}-c_{t}^{h}\right)-\lambda_{1 t}^{h}\left[u \frac{1}{M^{h}}\left(M^{h}-N_{t}^{h}\right)-\left(a+u \frac{N_{t}^{h}}{M^{h}}+g \frac{N_{t}^{c}}{M^{c}}\right)-k_{h}\right] \\
& \cdot W_{t}^{h}\left(A_{t}^{h}, A_{t}^{c}, p_{t}^{h}, p_{t}^{c}\right) \\
& -\lambda_{3 t}^{h} v \frac{1}{M^{h}}\left(M^{c}-N_{t}^{c}\right) W_{t}^{c}\left(A_{t}^{h}, A_{t}^{c}, p_{t}^{h}, p_{t}^{c}\right), \\
\dot{\lambda}_{2 t}^{h}= & -\lambda_{2 t}^{h}\left[z_{2} \frac{1}{L}\left(L-l_{t}^{c}\right)-\left(z_{1}+z_{2} \frac{l_{t}^{c}}{L}+z_{3} \frac{N_{t}^{c}}{M^{c}}\right)\left(L-l_{t}^{c}\right)-z_{4}\right] \\
& -\lambda_{3 t}^{h} \chi \frac{1}{L}\left(M^{c}-N_{t}^{c}\right) W_{t}^{c}\left(A_{t}^{h}, A_{t}^{c}, p_{t}^{h}, p_{t}^{c}\right), \\
\dot{\lambda}_{3 t}^{h}= & -\lambda_{1 t}^{h} g \frac{1}{M^{c}}\left(M^{h}-N_{t}^{h}\right) W_{t}^{h}\left(A_{t}^{h}, A_{t}^{c}, p_{t}^{h}, p_{t}^{c}\right)-\lambda_{2 t}^{h} z_{3} \frac{1}{M^{c}}\left(L-l_{t}^{c}\right) \\
& -\lambda_{3 t}^{h}\left[\gamma \frac{1}{M^{c}}\left(M^{c}-N_{t}^{c}\right)-\left(\alpha+v \frac{N_{t}^{h}}{M^{h}}+\gamma \frac{N_{t}^{c}}{M^{c}}+\chi \frac{l_{t}^{c}}{L}\right)-k_{c}\right] W_{t}^{c}\left(A_{t}^{h}, A_{t}^{c}, p_{t}^{h}, p_{t}^{c}\right)
\end{aligned}
$$


with $N_{0}^{h}=0, N_{0}^{c}=0, l_{0}^{c}=0, \lim _{t \rightarrow \infty} \lambda_{1 t}^{h} N_{t}^{h}=0, \lim _{t \rightarrow \infty} \lambda_{2 t}^{h} l_{t}^{c}=0, \lim _{t \rightarrow \infty} \lambda_{3 t}^{h} N_{t}^{c}=0, \lim _{t \rightarrow \infty} \lambda_{1 t}^{c} N_{t}^{h}=$ $0, \lim _{t \rightarrow \infty} \lambda_{2 t}^{c} l_{t}^{c}=0, \lim _{t \rightarrow \infty} \lambda_{3 t}^{c} N_{t}^{c}=0$.

\subsection{Numerical results}

Next we compute the optimal policies in a weak IPR context for a set of parameters. As a base case, we assume the set of parameters given Section 2, arbitrarily decomposing the market size $M=4000$ in 2000 units for illegal copies and 2000 for licensed products. We also tested other asymmetric decompositions without a strong impact on the results (in particular, the impact of small changes is discussed in the comparative statics section). We assume lower quality of the innovation for the pirates, and thus, slower growth of pirate product sales. For that reason, we consider $\alpha=0.001$, $\beta=0.00005, \sigma=0.0001, \gamma=0.15, v=0.15$, which are lower than the parameters considered in Section 2. For this set of parameters, in the context of the weak IPR protection with pirates, the optimal profits of the IPR holder and the pirates are $\Pi_{\text {piracy }}^{h}=5.6249 \cdot 10^{6}$ and $\Pi_{\text {piracy }}^{c}=2.7518 \cdot 10^{6}$, respectively. In the context of the weak IPR protection with licenses, the optimal profits of the IPR holder and the licensee are $\Pi_{l i c}^{h}=1.0620 \cdot 10^{7}$ and $\Pi_{l i c}^{l}=6.3513 \cdot 10^{5}$, respectively. The result suggests that the licensing strategy might be interesting for the IPR holder $\left(\Pi_{\text {lic }}^{h}>\Pi_{\text {piracy }}^{h}\right)$, but

not for the pirates $\left(\Pi_{l i c}^{l}<\Pi_{\text {piracy }}^{c}\right)$. As a consequence the license agreement is not implemented. Furthermore, recall that in a strong IPR context with analogous parameters, the optimal profit for monopolist is $\Pi_{m o n}^{h}=9.6860 \cdot 10^{6}$, so the difference of $\left(\Pi_{\text {mon }}^{h}-\Pi_{\text {piracy }}^{h}\right)=4.0611 \cdot 10^{6}$ is the financial cost of piracy for the IPR holder, i.e. the economic loss caused to the innovator because of a weak IPR regulation. The dynamics of the discounted profits in the equilibrium is similar for both the IPR holder and the pirates; i.e., a fast growth followed by an exponential decay to zero. At the maximum pirates achieve roughly 3 times the maximum level of discounted profits obtained by a licensee, but decay faster.

The previous result also suggests that although piracy may speed up the product diffusion of the IPR holder through word of mouth and communication of pirates (Figure 5 shows the sales diffusion in a market with pirates compared to that of a monopolist IPR holder), this advantage is not enough to compensate the innovator for the market-share loss. Under a licensing agreement, the royalties would reduce the damage, rendering $\Pi_{\text {lic }}^{h}=1.0620 \cdot 10^{7}$, which is higher than the return in a monopoly. However, pirates do not receive reciprocal benefits from the licensing contract. 


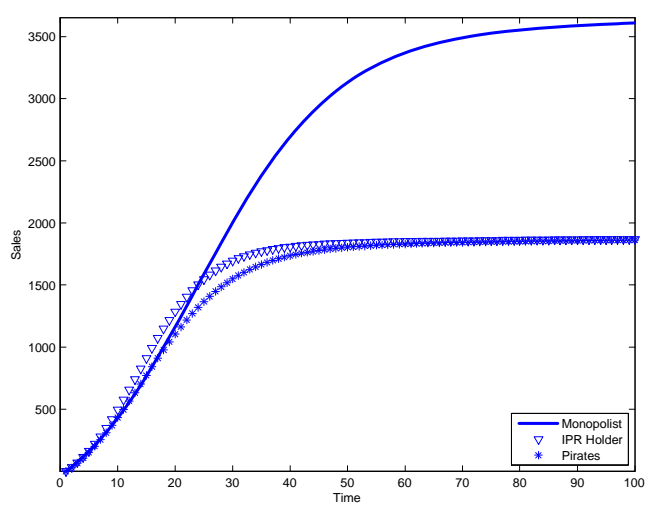

Figure 5: Sales diffusion in the context of weak IPR.

The dynamics pattern of the optimal discounted prices and marketing effort investments for weak IPR protection scenario is similar that of an analogous licensor in a strongly protected market. By contrast, pirates invest in advertising roughly $1 / 8$ of the IPR holder, and charge approximately half of its price.

\subsection{Comparative statics}

In this section we study the effect of parametric changes on the returns drawn from the different strategies in a weak IPR framework. Using the envelope theorem for differential games, we compute the impact of parameter change on the profits $\Pi_{l i c}^{h}, \Pi_{l i c}^{l}, \Pi_{\text {piracy }}^{h}, \Pi_{\text {piracy }}^{c}$ and the relative advantage of licensing for IPR holder $\Delta^{h}=\left(\Pi_{\text {lic }}^{h}-\Pi_{\text {piracy }}^{h}\right)$ and for pirates $\Delta^{l}=\left(\Pi_{\text {lic }}^{l}-\Pi_{\text {piracy }}^{c}\right)$. Table 2 shows numerical values of partial derivatives of the profit functions, $\partial \Delta^{h}\left(\theta_{0}\right) / \partial \theta_{i}$, and $\partial \Delta^{l}\left(\theta_{0}\right) / \partial \theta_{i}$ for the different parameters in the model; that is how "sensitive" the cumulative profits are to changes in the value of the parameters of the model considering a licensed and unlicensed market.

Table 2: Comparative statics for licensing and piracy strategies in the weak IPR framework 


\begin{tabular}{c||c|c|c|c|c|c|}
\hline$\theta$ & $\frac{\partial \Pi_{\text {lic }}^{h}\left(\cdot 10^{8}\right)}{\partial \theta}$ & $\frac{\partial \Pi_{\text {lic }}^{l}\left(\cdot 10^{8}\right)}{\partial \theta}$ & $\frac{\partial \Pi_{\text {piracy }}^{h}}{\partial \theta}\left(\cdot 10^{8}\right)$ & $\frac{\partial \Pi_{\text {piracy }}^{c}\left(\cdot 10^{8}\right)}{\partial \theta}$ & $\frac{\partial \Delta^{h}}{\partial \theta}\left(\cdot 10^{8}\right)$ & $\frac{\partial \Delta l}{\partial \theta}\left(\cdot 10^{8}\right)$ \\
\hline \hline$\alpha$ & -0.1468 & 0.3205 & 0.0478 & 0.0666 & -0.1946 & 0.2539 \\
\hline$v$ & -0.0400 & 0.0593 & 0.0091 & 0.0202 & -0.0491 & 0.0391 \\
\hline$\gamma$ & -0.0489 & 0.0726 & 0.0083 & 0.0185 & -0.0572 & 0.0541 \\
\hline$\mu$ & -0.4803 & -0.3269 & 0.3613 & 1.9359 & -0.8416 & -2.2628 \\
\hline$\delta$ & -0.7131 & -0.7767 & 12.9447 & -1.8911 & -13.6578 & 1.1144 \\
\hline$\beta$ & -0.1473 & 0.2510 & 0.0281 & 0.0584 & -0.1754 & 0.1926 \\
\hline$\sigma$ & -0.1497 & 0.2350 & 0.0468 & 0.0426 & -0.1965 & 0.1924 \\
\hline$k_{l}$ & 1.9515 & -2.2347 & -0.0387 & -0.2753 & 1.9902 & -1.9594 \\
\hline$\chi$ & -0.1407 & 0.2770 & 0.0381 & 0.0567 & -0.1788 & 0.2203 \\
\hline
\end{tabular}

\begin{tabular}{c||c|c|c|c|c|c|}
\hline$\theta$ & $\frac{\partial}{\partial \theta} \Pi_{\text {lic }}^{h}\left(\cdot 10^{8}\right)$ & $\frac{\partial \Pi_{\text {lic }}^{l}\left(\cdot 10^{8}\right)}{\partial \theta}$ & $\frac{\partial \Pi_{\text {piracy }}^{h}}{\partial \theta}\left(\cdot 10^{8}\right)$ & $\frac{\partial \Pi_{\text {piracy }}^{c}}{\partial \theta}\left(\cdot 10^{8}\right)$ & $\frac{\partial \Delta^{h}}{\partial \theta}\left(\cdot 10^{8}\right)$ & $\frac{\partial \Delta^{l}}{\partial \theta}\left(\cdot 10^{8}\right)$ \\
\hline \hline$z_{1}$ & 0.00024 & 0.000069 & 0.00013 & 0.00013 & 0.00011 & -0.000061 \\
\hline$z_{2}$ & 0.000088 & 0.000063 & 0.000079 & 0.000082 & 0.000009 & -0.000019 \\
\hline$z_{3}$ & 0.000001 & -0.00004 & 0.000041 & 0.000041 & -0.00004 & -0.000081 \\
\hline$z_{4}$ & -0.0064 & 0.0093 & -0.0031 & -0.0031 & -0.0033 & 0.0124 \\
\hline$z_{5}$ & -1177.53 & 1316.51 & 0 & 0 & -1177.53 & 1316.51 \\
\hline$z_{6}$ & -36.39 & 37.54 & 0 & 0 & -36.39 & 37.54 \\
\hline $\bar{r}$ & 0.00062 & -0.00062 & 0 & 0 & 0.00062 & -0.00062 \\
\hline$f$ & 0.00002 & -0.00002 & 0 & 0 & 0.00002 & -0.00002 \\
\hline$L$ & 0.0004 & -0.0006 & 0.00023 & 0.00023 & 0.00017 & -0.00083 \\
\hline
\end{tabular}

In the context of weak IPR markets, licensing is the recommendable strategy for the IPR holder because an increase of the pirates diffusion does not imply an increase of its profits (as pirates do not pay licensing fees). Similarly to the case of strong IPR markets, increasing the speed of licensee companies diffusion (larger $z_{1}, z_{2}, z_{3}$, and smaller $z_{4}, z_{5}, z_{6}$,) and the market potential of licensees $L$ makes licensing more attractive strategy.

If we keep $M$ constant, and increase $M^{h}$ whereas decreasing $M^{c}$ we can consider the marginal change in the licensing advantage for IPR holder $\left(\partial \Delta^{h} / \partial M^{h}-\partial \Delta^{h} / \partial M^{c}\right)=-1.03 \times 10^{-4}<0$, and also the marginal change in the licensing advantage for pirates $\left(\partial \Delta^{l} / \partial M^{h}-\partial \Delta^{l} / \partial M^{c}\right)=$ $6.242 \times 10^{-3}>0$. When the IPR increases its share of the total market potential with respect to the pirates, then licensing is less (more) attractive for the licensor (pirates).

Table 2 also shows that $\partial \Delta^{h} / \partial \theta$ and $\partial \Delta^{l} / \partial \theta$ generally take values of opposite signs with the exception of those related to prices. This result implies that the more desirable licensing is for the IPR holder, the less willing the pirates are to accept the licensing contract. And vice versa - when a parametric change makes licensing more attractive for the pirates, the IPR holder is less willing to offer a licensing contract. Although we do not completely rule out the possibility of licensing contract viability, these results show that obviously licensing event is less common in weak IPR framework. This result goes in line with empirical evidence by Arora and Ceccagnoli (2006), Gambardella et al. (2007), and Anand and Khanna (2000). 
Previous research suggests that piracy can be beneficial for an IPR holder, since pirates accelerate diffusion via word-of-mouth (see Givon et al. 1995, and Givon et al. 1997). We also found some interesting insights studying the financial loss of the IPR holder due to piracy, that is the difference between the partial derivatives of profits of the IPR holder in a monopolistic scenario (see $\partial \Pi_{\text {mon }}^{h} / \partial \theta$ in Table 1 ) and those when pirates are present (see $\partial \Pi_{\text {piracy }}^{h} / \partial \theta$ in Table 2 ). The lower the coefficient of innovation (parameter $a$ ) is, the lower it is the IPR holder's financial loss caused by piracy. In other words, when the innovation parameter of the IPR holder is very small, the IPR holder could be better off tolerating some piracy. This goes in line with the results of Prasad and Mahajan (2003), who find that the lower the coefficient of innovation, the higher is the optimal tolerance level of piracy. Also, the higher the word of mouth parameter $u$ is, the more willing the IPR holder is to be in a monopolist position. This is because for a high $u$ the IPR holder has sufficient word of mouth and it is less willing to tolerate pirates (Prasad and Mahajan, 2003 , find that piracy toleration is lower when word of mouth coefficient is either very small or very large). Prasad and Mahajan (2003) also find a minor effect of discount rate on piracy tolerance. In contrast, these results suggest that the higher the discount rate $i$ is, the smaller it is the IPR holder financial loss due to the piracy. This result is reasonable, since when the discount rate is higher, faster diffusion of sales becomes more crucial for the IPR holder. Thus, the IPR holder may even prefer pirates to have some part of the total market potential, given that pirates speed up the diffusion.

\section{Empirical application}

This section presents an empirical application of the proposed licensing model to incandescent light bulbs industry in the United Kingdom (UK). Light bulb industry emerged in the end of 19th century. After a number of years cooperating though prices and patent licensing, in 1925 the world leading lamp manufacturers negotiated the General Patent and Business Development Agreement (also known as the "Phoebus Agreement" after the administrative office-S.A. Phoebus- located in Geneva) originally set up to 1955, but broken to an end by the second world war. The Phoebus Agreement divided world markets, allocating to each party the right to the same annual proportion of the total business in each territory as they had in 1924, and set product standards. The Electric Lamp Manufacturers' Association (E.L.M.A.) got the control for lamp manufacturing in UK. (E.L.M.A. included British Thomson-Houston Co. Ltd., Edison Swan Electric Co. Ltd., Metropolitan-Vickers Electrical Co. Ltd., General Electric Co. Ltd., Philips Electrical Ltd., Stella Lamp Co. Ltd., Cryselco Ltd., Siemens Electric Lamps \& Supplies Ltd., Crompton Parkinson Ltd., British Electric Lamps Ltd., and Aurora Lamps Ltd.)

In 1937 the monopolist consortium E.L.M.A granted a non-exclusive non-transferable license to produce and sell electric lamps in UK to British Luma Co-operative Electric Lamp Society Ltd. (henceforth British Luma), a cooperative of small UK manufacturers. The output sold by British Luma was slightly larger than the sum of productions of the two smallest companies in E.L.M.A. In this section we study the E.L.M.A. and British Luma agreement using the licensing model to obtain structural explanations for their decisional, and compute optimal patterns for their profits and sales. We use sales data from UK Monopolies Commission Report on the Supply of Electric Lamps. The yearly lamp production data extends from 1924 till 1950. The licensing contract also

specifies the number of lamp units that the Licensee is permitted to sell or otherwise dispose of for the duration of the License from 1937 till 1947. The difference between total lamp production and 
Licensee's sales is recorded as the Licensor annual sales. We use linear interpolation to obtain data for the missing observations. For this particular case, we consider that the decision problems faced by Licensor and the Licensee at the year of 1937 are given by the following structure:

- The licensee British Luma solves the problem

\begin{tabular}{|ll|}
\hline $\max \Pi_{l i c}^{l}=$ & $\int_{0}^{\infty} e^{-i t}\left(\left(p_{t}^{l}-c\right)(1-r) N_{t}^{l}\right) d t$ \\
s.t. & $(2),(3)$,
\end{tabular}

- The licensor E.L.M.A. solves the problem

$\begin{array}{ll}\max \Pi_{l i c}^{h}= & \int_{0}^{\infty} e^{-i t}\left(\left(p_{t}^{h}-c\right) N_{t}^{h}+\left(p_{t}^{l}-c\right) r N_{t}^{l}\right) d t \\ \text { s.t. } & (2),(3)\end{array}$

where

$$
\dot{N}_{t}^{h}=\left[\left(a+u\left(\frac{N_{t}^{h}}{M^{h}}+\frac{N_{t}^{l}}{M^{l}}\right)\right)\left(M^{h}-N_{t}^{h}\right)\right]\left[1-m\left(e^{r t} \bar{p}-p_{t}^{h}\right)^{2}+d\left(e^{r t} \bar{p}-p_{t}^{l}\right)^{2}\right]
$$

and

$$
\dot{N}_{t}^{l}=\left[\left(\alpha+v\left(\frac{N_{t}^{h}}{M^{h}}+\frac{N_{t}^{l}}{M^{l}}\right)\right)\left(M^{l}-N_{t}^{l}\right)\right]\left[1+\mu\left(e^{r t} \bar{p}-p_{t}^{h}\right)^{2}-\delta\left(e^{r t} \bar{p}-p_{t}^{l}\right)^{2}\right]
$$

and $N_{0}^{h}=N_{1937}, N_{0}^{l}=0$.

Note that, by the licensing contract, the Licensee pays a $3 \%$ royalty of the net selling price to the licensor, i.e. $r=0.03$. By the contract the licensees should not supply lamps which are different in size characteristics from those sold by the Licensor. Thus, we assume that the word of mouth effects of licensor and licensee sales are the same. Furthermore, the growth equation for licensees number is absent from the system of state equations as there is only one licensee company throughout the licensing period. We did not have data on advertising, and therefore it was not included in the model. Two different market potentials were considered, similarly to the weak IPR framework, as the agreement restricted the market potential for British Luma.

Regarding of the pricing of the electrical bulbs, by the licensing contract, British Luma does not take decision over the prices. In contrast, we consider how price competition affects the sales diffusion paths. We set the market potentials as $M^{h}=3000 \bullet 10^{5}$ and $M^{l}=40 \bullet 10^{5}$, and obtain the least squares estimators of the coefficients of innovation and imitation: $a=0.012, u=0.061$, $\alpha=-0.15, v=0.32, m=3.3, \delta=24.15$, with $d=1$ and $\mu=10$. Using the estimated parameter values, a discount factor $i=0.08$, an average measure of desirable price $\bar{p}=0.05 \&$ for a unit of bulb, and a unit cost $0.03 £$, we solve numerically the dynamic game between the Licensor and the Licensee. The optimal discounted lifetime profits for E.L.M.A and British Luma are $1.26 \bullet 10^{8} £$ 
and $8.45 \bullet 10^{5} £$, respectively. Figure 6 depicts the optimal sales path for both companies over the considered time period, as well as the empirical data. Notice that between 1939 to 1945 the second world war damaged European lamp sales even for the posterior years, and Phoebus Agreement was ended by that time.
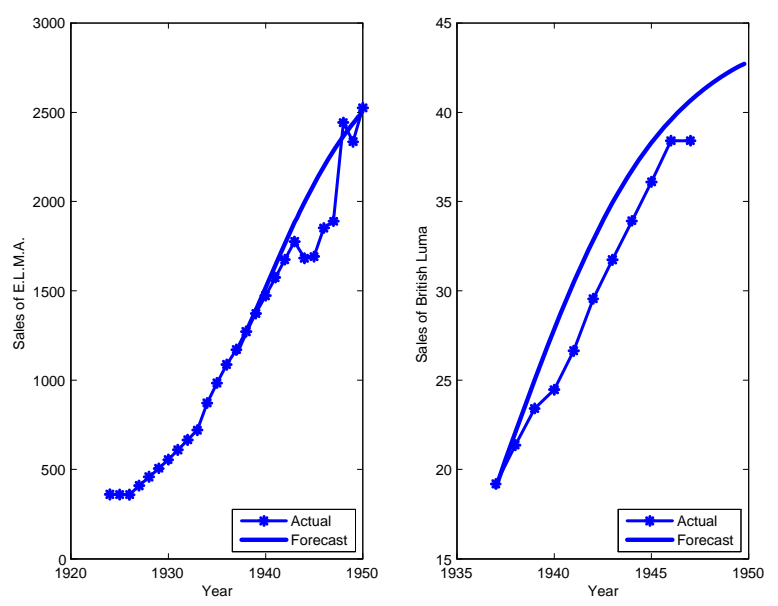

Figure 6. Sales of E.L.M.A. and British Luma

A manager of a company which faces a decision to license (or alternatively, to become a licensee) could perform a similar analysis to get a measure of total lifetime profits from licensing and optimal product sales path. This would help to make a rigorous decision about to license or not. Also, by possessing external measures of sales sensitivity to marketing mix variables the manager could use the model to deduce optimal marketing mix decisions. Importantly, the analysis takes into account the word of mouth acceleration effect of the licensee sales on sales growth of the licensor and vice versa.

\section{Conclusions}

On a first look, licensing IPR is a risky decision that may imply stronger competition and rent dissipation. Besides, royalties are often low, and licensers capture only a small fraction of the rents from the innovation (e.g., Caves et al. 1983, Arora 1997). Arrow (1962) remarks show how striking this feature is: "Patent royalties are generally so low that the profits from exploiting one's own invention are not appreciably greater than those derived from the use of others' knowledge". Why the firm that has developed the knowledge cannot demand a greater share of the resulting profits?

An obvious reason can be found in a dynamic context. This paper finds that the increase in licensor profits is due to the acceleration of the sales diffusion process, and the advantage of using licensee marketing effort and word of mouth compared to monopolistic position. We have found that the consequences of this strategy are different when the industry has strong IPR protection compared to the scenario of a weakly protected market. 
In markets with strong IPR protection, both IPR holders and licensees can benefit from licensing. For the IPR holder licensing is a beneficial strategy because there is an increase in profits, in comparison to the case of monopoly. This result stands in contrast to the results drawn from static licensing models. In particular, one of the results of Arora and Fosfuri (2003) is that a monopolist IPR holder would never license. Licensing generates two forces on licensor's profit: revenue effect (licensing payments by the licensees to the IPR holder) and rent dissipation effect (erosion of licensor's profit due to additional competition in the product market). When the IPR holder is a monopolist in a product market, the rent dissipation effect is greater than the revenue effect whenever industry profits are maximized by a monopoly. Thus, licensing does not take place.

The proposed dynamic model allows to consider a third effect which has been neglected in static models of licensing: sales diffusion acceleration. Competition between licensor and licensees results in faster sales diffusion due to higher innovation awareness through the combined advertising and cross word-of-mouth effects. As a result, for a monopolistic IPR holder sales diffusion acceleration and revenue effects dominate rent dissipation effect (loss of the market to the licensees), and licensing takes place. In comparative statics we also analyze how sensitive licensing implementation is to model parameters.

Regarding industries with weak IPR protection, the empirical evidence suggests that licensing is less common (Anand and Khanna 2000, Arora and Ceccagnoli 2006, Gambardella et al. 2007). We study licensing decision in this framework when IPR holder faces weak competition by pirate companies who sell copy products with lower quality. From IPR holder's perspective, licensing is a beneficial decision due to licensing payments and faster sales diffusion. However, pirates are better off when selling copy products than licensed products with higher quality as in the last case they have to pay licensing fees to the IPR holder. Although not completely ruled out, comparative statics suggests that licensing is less desirable strategy in the context of weak IPR protection from either the perspective of the IPR holder or the pirates. This can partially explain, for instance, the slowness of discography industry to allow licensing through the internet to stop the last decade boom of piracy. Pirates are less interested in this arrangement.

We have also obtained firms' optimal policies for marketing mix and licensing fees in both of IPR contexts. Interestingly, in the protected IPR framework, the discounted prices charged by monopolistic, licensor and licensees are not too different. By contrast, the weakly protected IPR context shows higher differences on the average prices (which can be explained by the higher independence between the diffusion process of pirates and IPR holder). In case of licensing, optimal fixed fee as well as royalties decrease to zero exponentially. The discounted advertising investments decrease at an exponential rate in all the cases.

Managerial Implications: Radical product innovations considerably vary in their take-off times and the speed of diffusion. Most managers favor rapid acceleration of sales diffusion in order to receive quicker returns. As far as we know, this is the first paper that analyzes licensing as a strategy to accelerate the diffusion of radical product innovation in different IPR frameworks. We showed that licensing would provide considerable benefits to a firm, for a certain set of parameter values analyzing the robustness of this property using comparative statics. Thus, a manager could conduct a similar analysis to decide for the benefits of product licensing and to have optimal marketing mix and licensing decisions over time. The empirical application illustrates how the proposed model can be adapted to different data sets.

Limitation and Future Research: The proposed modeling approach leaves open many possibilities for future research. First, in the dynamic game solution we assume open-loop information 
structure, but there are other alternatives. Future work could extend the analysis to industries with more information using a closed loop or a Stackelberg equilibrium, although the computational task to solve these models is formidable. Second, we assume a model specification that builds upon the new product diffusion literature. Although the specification is well grounded, we consider that empirical testing of the model would be important. Unfortunately, the richness of the required data makes it somehow difficult. To respond this challenge, researchers have suggested to use experimental designs as well as computer based simulations (e.g. Montaguti et al. 2002). We clearly followed the second strategy. At least, the comparative static analysis yields several hypotheses, some of which are testable and we leave it for further research.

\section{References}

[1] Agarwal, R., B. L Bayus (2002) The market evolution and sales takeoff of product innovations. Management Science 48: 1024-1041.

[2] Anand, B., T. Khanna (2000) The structure of licensing contracts. Journal of Industrial Economics 48: 103-135.

[3] Arora, A. (1997) Patents, licensing, and market structure in the chemical industry. Research Policy 26: 391-403.

[4] Arora, A., A. Fosfuri (2003) Licensing the market for technology. Journal of Economic Behavior \& Organization 52: 277-295.

[5] Arora, A., M. Ceccagnoli (2006) Patent protection, complementary assets, and firms' incentives for technology licensing. Management Science 52: 293-308.

[6] Arrow, K. (1962) Comments on case studies. in R.R.Nelson (ed.) The Rate and Direction of Inventive Activity: Economic and Social Factors, Princeton, NJ, Princeton University Press

[7] Ascher, U., R. M. M. MattheiJ, R. Russell (1995) Numerical Solution of Boundary Value Problems for Ordinary Differential Equations. SIAM's Classics in Applied Mathematics, 13, SIAM, Philadelphia.

[8] BAss, F. (1969) A new product growth model for consumer durables. Management Science 15: $215-227$.

[9] Bass, F., T. KRishnan, D. Jain (1994) Why the Bass model fits without decision variables. Marketing Science 13: 203-223.

[10] Bass, F., D. Jain, T. Krishnan (2000) Modeling the marketing-mix in new-product diffusion, in Mahajan, V., E. Muller, and Y. Wind, eds. New Product Diffusion Models, Kluwer Academic Publishers, New York.

[11] Bayus, B., N. Kim, A. Shocker (2000) Growth Models for Multiproduct Interactions: Current Status and New Directions, in V. Mahajan, E. Muller, and Y. Wind (eds), New Product Diffusion Models, Kluwer. 
[12] Bertsekas, D. (1995) Dynamic programming and optimal control. Vols.1 and 2. Athena Scientific, Belmont, MA.

[13] Caputo, M. (2007) The envelope theorem for locally differentiable Nash equilibria of finite horizon differential games. Games and Economic Behavior 61: 198-224.

[14] Caves, R., H. Crookel, J. Killing (1983) The imperfect market for technology licensing. Oxford Bulletin of Economics and Statistics 54: 249-267

[15] Chandrasekaran, D. G. Tellis (2007) A critical review of marketing research on diffusion of new products, Edited by Naresh K. Malhotra: Review of Marketing Research, Volume 3, Chapter 2, , M.E. Sharpe, Inc.

[16] Chiang, A. (1992) Elements of Dynamic Optimization. McGraw Hill, New York.

[17] Conner, K. (1995) Obtaining strategic advantage from being imitated: When can encouraging "clones" pay? Management Science 41: 209-225.

[18] Dockner, E., S. Jorgensen (1988) Optimal pricing strategies for new products in dynamic oligopolies. Marketing Science 7: 315-334.

[19] Epstein, L. (1978) The Le Châtelier principle in optimal control problems. Journal of Economic Theory 19: 103-122.

[20] Foster, J., P. Golder, G. Tellis (2004) Predicting Sales Takeoff for Whirlpool's New Personal Valet. Marketing Science 23: 180-191.

[21] Fruchter, G., C. Van den Bulte (2010) Why the Generalized Bass Model Leads to Dubious Optimal Advertising Policies. Working Paper

[22] Gambardella, A., P. Giuri, A. Luzzi (2007) The market for patents in Europe. Research Policy 36: 1163-1183.

[23] Givon, M., V. Mahajan, E. Muller (1995) Software piracy: Estimation of lost sales and the impact on software diffusion. Journal of Marketing 59: 29-37.

[24] Givon, M., V. Mahajan, E. Muller (1997) Assessing the relationship between the userbased market share and unit sales-based market share for pirated software brands in competitive markets. Technological Forecasting $\mathcal{E}$ Social Change 55: 131-144.

[25] Golder, P., G. Tellis. (1997) Will it ever fly? Modeling the takeoff of really new consumer durables. Marketing Science 16: 256-270.

[26] Golder, P., G. Tellis. (2004) Growing, growing, gone: Cascades, diffusion, and turning points in the product life cycle. Marketing Science 23: 207-218.

[27] Gupta, S., C. Mela, J. M. Vidal-Sanz (2006). The value of a "free" customer, Working paper 07-035, Harvard Business School (www.hbs.edu/research/pdf/07-035.pdf). (A 2009 version is available as a Working Paper from Universidad Carlos III de Madrid, Business Economics Series 09-29-03, http://hdl.handle.net/10016/3883) 
[28] Horsky, D., L. Simon (1983) Advertising and the diffusion of new products. Marketing Science 2: 1-17

[29] Horsky, D., K. Mate (1988) Dynamic advertising strategies of competing durable good producers. Marketing Science 7: 356-367.

[30] JudD, K. (1998) Numerical methods in economics. The MIT press.

[31] KALish, S. (1985) A new product adoption model with price, advertising, and uncertainty Management Science 31: 1569-1585.

[32] Kamien, M. (1992) Patent licensing. In: R.J. Aumann and S. Hart, Editors, Handbook of Game Theory, North-Holland, Amsterdam

[33] Kamien, M., N. Schwartz (1981) Dynamic Optimization. North Holland, New York.

[34] Klepper, S. (1997). Industry life cycles. Indust. Corporate Change 6: 145-181.

[35] Krishnan, T., F. Bass, D. Jain (1999) Optimal Pricing Strategy for New Products. Management Science 45: 1650-1663.

[36] LaFrance, J., D. Barney (1991) The envelope theorem in dynamic optimization. Journal of Economic Dynamics and Control 15: 355-385.

[37] Libai, B., E. Muller, R. Peres (2009) The Role of Within-Brand and Cross-Brand Communications in Competitive Growth. Journal of Marketing 73: 19-34.

[38] Lions, J. (1971) Optimal Control of Systems Governed by Partial Differential Equations. Springer Verlag, New York.

[39] Mahajan, V., E. Muller (1996) Timing, diffusion, and substitution of successive generations of technological innovations: The IBM mainframe case. Technological Forecasting and Social Change 51: 109-132.

[40] Mahajan, V., E. Muller, F. Bass (1990) New product diffusion models in marketing: A review and directions for research. Journal of Marketing Research 54: 1-26.

[41] Mahajan, V., E. Muller, F. Bass (1993) New-product diffusion models, In J. Eliashberg and G. L. Lilien (eds.), Handbooks in Operations Research and Management Science, Vol. 5, Elsevier Science Publishers (North Holland), Amsterdam, 349-408

[42] Montaguti, E., S. Kuester, T. Robertson (2002) Entry strategy for radical product innovations: A conceptual model and propositional inventory. International Journal of Research in Marketing 19: 21-42

[43] Muller, E., R. Peres, V. Mahajan (2007) Innovation Diffusion and New Product Growth: Beyond Interpersonal Communications. Working Paper (http://www.hitechmarkets.net/)

[44] Norton, J., F. Bass (1987) A diffusion theory model of adoption and substitution for successive generations of high-technology products. Management Science 33: 1069-1086. 
[45] Parker, P., H. Gatignon (1994) Specifying Competitive Effects in Diffusion Models: An Empirical Analysis. International Journal of Research in Marketing, 11: 17-40.

[46] Pontryagin, L., V. Boltyanskit, R. Gamkrelidze, E. Mishenko (1964) The mathematical theory of optimal processes. Mc Millan, New York.

[47] Prasad, A., V. Mahajan (2003) How many pirates should a software firm tolerate: an analysis of piracy protection on the diffusion of software. International Journal of Research in Marketing 20: 337-353

[48] Robinson, R., C. Lakhani (1975) Dynamic price models for new product planning. Management Science 21: 1113-22.

[49] Rogers, E. (1995) Diffusion of Innovation, 4th edition, The Free Press, New York

[50] Savin, S., C. Terwiesch (2005) Optimal Product Launch Time in a Duopoly: Balancing Lifecycle Revenues with Product Cost. Operations Research 53: 26-47

[51] Shapiro, C. (1985) Patent licensing and R\&D rivalry. American Economic Review 75: 23-30

[52] Shepard, A. (1987) Licensing to enhance demand for new technologies. RAND Journal of Economics 18: 360-368

[53] Seierstad, A. (1982) Differentiability properties of the optimal value function in control theory. Journal of Economic Dynamics and Control 4: 303-310.

[54] Seierstad, A., K. Sydsaeter (1987) Optimal Control Theory with Economic Applications. Advanced Textbooks in Economics, (C. J. Bliss and M. D. Intriligator Editors ), Vol. 24. North-Holland, New York.

[55] Stoneman, P., N. Ireland (1983) The role of supply factors in the diffusion of new process technologies. Economic Journal Supplement (March): 65-77.

[56] Stremersch, S., E. Muller, R. Peres (2010) Does new product growth accelerate across technology generations? Marketing Letters 21: 103-120.

[57] Sultan F., J. Farley, D. Lehmann (1990) A meta-analysis of applications of diffusion models. Journal of Marketing Research 27: 70-77.

[58] Tellis, G., S. Stremersch, E. Yin (2003) The International Takeoff of New Products: The Role of Economics, Culture, and Country Innovativeness. Marketing Science 22: 188-208.

\section{Appendix}

Consider $N$ players each one of them setting a set of control variables $u_{i t}$, a deterministic dynamic system $\dot{x}_{t}=g\left(x_{t}, u_{t}, t\right), x(0)=x_{0}$ with $u_{t}=\left(u_{1 t}, \ldots, u_{N t}\right)$. In a standard differential game, each player maximizes the profits $\Pi^{i}=\int_{0}^{\infty} G^{i}\left(u_{t}, x_{t}, t\right) d t$ subject to a dynamic system contraints, where $G^{i}$ and $g$ are continuously differentiable functions. In an (open-loop) Nash equilibrium $\left(x^{*}, u^{*}\right)$

$$
\Pi^{i}\left(x^{*}, u_{1}^{*}, \ldots, u_{N}^{*}\right)=\max _{u_{i}, x} \Pi^{i}\left(x, u_{1}^{*}, \ldots, u_{i-1}^{*}, u_{i}, u_{i+1}^{*}, \ldots, u_{N}^{*}\right),
$$


subject to the dynamic system constraint, for $i=1, \ldots, N$. The open-loop Nash equilibrium $\left\{x^{*}, u_{1}^{*}, \ldots, u_{N}^{*}\right\}$ satisfies the first order conditions:

$$
\frac{\partial H^{i}}{\partial u_{i t}}=0, \frac{\partial H^{i}}{\partial \lambda_{i t}}=\dot{x}_{t}, \dot{\lambda}_{i t}=-\frac{\partial H^{i}}{\partial x_{t}}
$$

for $i=1, \ldots, N$, where $H^{i}\left(x_{t}, u_{1 t}, \ldots u_{N t}, t\right)=G^{i}\left(x_{t}, u_{1 t}, \ldots u_{N t}, t\right)+\lambda_{i t} g\left(x_{t}, u_{1 t}, \ldots u_{N t}, t\right)$ is the Hamiltonian of player $i$. By contrast, the closed-loop Nash (i.e. feedback) equilibrium $\left(x^{* *}, u^{* *}\right)$ is defined when (13) conditions are redefined in terms of the optimal response by other players to the state of the system, i.e.

$$
\Pi^{i}\left(x^{* *}, u_{1}^{* *}, \ldots, u_{N}^{* *}\right)=\max _{u_{i}, x} \Pi^{i}\left(x, u_{1}^{* *}(x), \ldots, u_{i-1}^{* *}(x), u_{i}, u_{i+1}^{* *}(x), \ldots, u_{N}^{* *}(x)\right),
$$

subject to the dynamic system constraint, for $i=1, \ldots ., N$. The closed-loop Nash equilibrium satisfies the HJB first order conditions:

$$
\frac{\partial H^{i}}{\partial u_{i t}}=0, \frac{\partial H^{i}}{\partial \lambda_{i t}}=\dot{x}_{t}, \dot{\lambda}_{i t}=-\frac{\partial H^{i}}{\partial x_{t}}-\sum_{j \neq i} \frac{\partial H^{i}}{\partial u_{j t}} \frac{\partial u_{j t}}{\partial x_{t}}
$$

for $i=1, \ldots, N$, where the terms $\left\{\partial u_{j t} / \partial x_{t}\right\}_{j \neq i}$ means that the $i-t h$ player anticipates the competitors' reaction to changes in the state variable when the player sets its policy, and these reactions are respectively weighted by their impact in the i-th player Hamiltonian $\partial H^{i} / \partial u_{j t}$. When $\partial u_{j t} / \partial x_{t}=0$ or $\partial H^{i} / \partial u_{j t}=0$ for all pairs $i \neq j$, then the open-loop and the closed-loop equilibrium are identical. Once the solution is computed we can evaluate the optimal values $\Pi^{* i}$ for each player at equilibrium. Finally, a Stackelberg differential game equilibrium assumes asymmetric information, such that informed leaders behave as in the closed-loop equilibrium, and the ignorant followers behave as in an open-loop equilibrium. For a detailed introduction to optimal control and differential games, see e.g. Pontryagin et al. (1964), Lions (1971), Kamien and Schwartz (1981), Seierstad and Sydsaeter (1987), Chiang (1992) and Bertsekas (1995).

Regarding the comparative statics, let us assume that the state and profit functions depend upon certain parameters $\theta \in \Theta \subset \mathbb{R}^{K}$ where $\Theta$ is an open set, so that $g_{\theta}\left(x_{t}, u_{t}, t\right)$ and $G_{\theta}^{i}\left(u_{t}, x_{t}, t\right)$ are smooth functions on $\Theta$. Then the envelop-theorem for differential games states that,

$$
\left.\frac{\partial \Pi_{\theta}^{* i}}{\partial \theta}\right|_{\theta=\theta_{0}}=\left.\int_{0}^{\infty}\left[\frac{\partial H^{i}\left(x_{t}, u_{t}, t\right)}{\partial \theta}+\sum_{j \neq i} \frac{\partial H^{i}\left(x_{t}, u_{t}, t\right)}{\partial u_{j t}} \frac{\partial u_{j t}}{\partial \theta}\right]\right|_{\theta=\theta_{0}} d t
$$

and this result is valid for both, open-loop and closed-loop equilibrium. A simple proof can be found, e.g., in LaFrance et al. (1991) for the case when $N=1$, and in Caputo (2007) for differential games.

Next we present the proofs of the results included in the paper.

\section{Proof. (Proposition 1)}


We define the HJB equation,

$$
\begin{aligned}
H_{\text {mon }}^{h}\left(N_{t}^{h}, p_{t}^{h}, A_{t}^{h}, t\right)= & G^{h}\left(p_{t}^{h}, A_{t}^{h}, N_{t}^{h}, t\right)+\lambda_{t}^{h} g^{h}\left(p_{t}^{h}, A_{t}^{h}, N_{t}^{h}, t\right), \\
G^{h}\left(p_{t}^{h}, A_{t}^{h}, N_{t}^{h}, t\right)= & e^{-i t}\left(\left(p_{t}^{h}-c_{t}^{h}\right) N_{t}^{h}-A_{t}^{h}\right), \\
g^{h}\left(p_{t}^{h}, A_{t}^{h}, N_{t}^{h}, t\right)= & {\left[\left(a+u \frac{N_{t}^{h}}{M}\right)\left(M-N_{t}^{h}\right)-k_{h} N_{t}^{h}\right] } \\
& \times\left(1+b \ln A_{t}^{h}-m\left(e^{r t} \bar{p}-p_{t}^{h}\right)^{2}\right)
\end{aligned}
$$

The maximum principle conditions are:

$$
\begin{aligned}
0 & =\frac{\partial}{\partial A^{h}} H_{m o n}^{h}=\frac{\partial}{\partial A^{h}} G_{t}^{h}+\lambda_{t}^{h} \frac{\partial}{\partial A^{h}} g_{t}^{h}, \\
0 & =\frac{\partial}{\partial p^{h}} H_{m o n}^{h}=\frac{\partial}{\partial p^{h}} G_{t}^{h}+\lambda_{t}^{h} \frac{\partial}{\partial p^{h}} g_{t}^{h}, \\
\dot{N}_{t}^{h} & =\frac{\partial}{\partial \lambda^{h}} H_{m o n}^{h}=g^{h}\left(p_{t}^{h}, A_{t}^{h}, N_{t}^{h}, t\right), \\
\dot{\lambda}_{t}^{h} & =-\frac{\partial}{\partial N^{h}} H_{m o n}^{h}=-\frac{\partial}{\partial N^{h}} G_{t}^{h}-\lambda_{t}^{h} \frac{\partial}{\partial N^{h}} g_{t}^{h},
\end{aligned}
$$

with $N_{0}^{h}=0, \lambda_{t}^{h} \rightarrow 0$. From the first condition:

$$
\begin{aligned}
0 & =-e^{-i t}+\lambda_{t}^{h}\left[\left(a+u \frac{N_{t}^{h}}{M}\right)\left(M-N_{t}^{h}\right)-k_{h} N_{t}^{h}\right] \frac{b}{A_{t}^{h}} \\
& \Rightarrow A_{t}^{h}=b e^{i t} \lambda_{t}^{h}\left[\left(a+u \frac{N_{t}^{h}}{M}\right)\left(M-N_{t}^{h}\right)-k_{h} N_{t}^{h}\right]
\end{aligned}
$$

The second condition leads to:

$$
\begin{aligned}
0 & =e^{-i t} N_{t}^{h}+\lambda_{t}^{h} 2 m\left(e^{r t} \bar{p}-p_{t}^{h}\right)\left[\left(a+u \frac{N_{t}^{h}}{M}\right)\left(M-N_{t}^{h}\right)-k_{h} N_{t}^{h}\right] \\
p_{t}^{h} & =e^{r t} \bar{p}+\frac{e^{-i t} N_{t}^{h}}{\lambda_{t}^{h} 2 m\left[\left(a+u \frac{N_{t}^{h}}{M}\right)\left(M-N_{t}^{h}\right)-k_{h} N_{t}^{h}\right]}
\end{aligned}
$$


From the third and fourth conditions:

$$
\begin{aligned}
\dot{N}_{t}^{h}= & {\left[\left(a+u \frac{N_{t}^{h}}{M}\right)\left(M-N_{t}^{h}\right)-k_{h} N_{t}^{h}\right]\left(1+b \ln A_{t}^{h}-m\left(e^{r t} \bar{p}-p_{t}^{h}\right)^{2}\right) } \\
\dot{\lambda}_{t}^{h}= & -e^{-i t}\left(p_{t}^{h}-c_{t}^{h}\right) \\
& -\lambda_{t}^{h}\left(\frac{u}{M}\left(M-N_{t}^{h}\right)-\left(a+u \frac{N_{t}^{h}}{M}\right)-k_{h}\right)\left(1+b \ln A_{t}^{h}-m\left(e^{i t} \bar{p}-p_{t}^{h}\right)^{2}\right)
\end{aligned}
$$

\section{Proof. (Proposition 2)}

A) First we consider the licensee's decisions, and define the HJB equation of the licensee's problem $H_{\text {lic }}^{l}=H_{\text {lic }}^{l}\left(r_{t}^{h}, f_{t}^{h}, A_{t}^{h}, A_{t}^{l}, p_{t}^{h}, p_{t}^{l}, N_{t}^{h}, l_{t}, N_{t}^{l}, t\right)$ as:

$$
\begin{aligned}
H_{\text {lic }}^{l}= & G^{l}\left(p_{t}^{l}, A_{t}^{l}, N_{t}^{l}, t\right)+\lambda_{t 1}^{l} g_{1}^{l}+\lambda_{t 2}^{l} g_{2}^{l}+\lambda_{t 3}^{l} g_{3}^{l} \\
G^{l}= & e^{-i t}\left(\left(p_{t}^{l}-c_{t}^{l}-r_{t}^{h}\right) N_{t}^{l}-A_{t}^{l}-f_{t} l_{t}\right) \\
g_{1}^{l}= & {\left[\left(a+u \frac{N_{t}^{h}}{M}+g \frac{N_{t}^{l}}{M}\right)\left(M-N_{t}^{h}-N_{t}^{l}\right)-k_{h} N_{t}^{h}\right] } \\
& \times W_{t}^{h}\left(A_{t}^{h}, A_{t}^{l}, p_{t}^{h}, p_{t}^{l}\right) \\
g_{2}^{l}= & {\left[\left(z_{1}+z_{2} \frac{l_{t}}{L}+z_{3} \frac{N_{t}^{l}}{M}\right)\left(L-l_{t}\right)-z_{4} l_{t}\right] L_{t}\left(f_{t}^{h}, r_{t}^{h}\right), } \\
g_{3}^{l}= & {\left[\left(\alpha+v \frac{N_{t}^{h}}{M}+\gamma \frac{N_{t}^{l}}{M}+\chi \frac{l_{t}}{L}\right)\left(M-N_{t}^{h}-N_{t}^{l}\right)-k_{l} N_{t}^{l}\right] } \\
& \times W_{t}^{l}\left(A_{t}^{h}, A_{t}^{l}, p_{t}^{h}, p_{t}^{l}\right)
\end{aligned}
$$

with

$$
\begin{aligned}
W_{t}^{h}\left(A_{t}^{h}, A_{t}^{l}, p_{t}^{h}, p_{t}^{l}\right) & =1+b \ln \left(A_{t}^{h}\right)+s \ln \left(A_{t}^{l}\right)-m\left(e^{r t} \bar{p}-p_{t}^{h}\right)^{2}+d\left(e^{r t} \bar{p}-p_{t}^{l}\right)^{2} \\
W_{t}^{l}\left(A_{t}^{h}, A_{t}^{l}, p_{t}^{h}, p_{t}^{l}\right) & =1+\beta \ln \left(A_{t}^{h}\right)+\sigma \ln \left(A_{t}^{l}\right)+\mu\left(e^{r t} \bar{p}-p_{t}^{h}\right)^{2}-\delta\left(e^{r t} \bar{p}-p_{t}^{l}\right)^{2} \\
L_{t}\left(f_{t}^{h}, r_{t}^{h}\right) & =1-z_{5}\left(e^{r t} \bar{f}-f_{t}^{h}\right)^{2}-z_{6}\left(e^{r t} \bar{r}-r_{t}^{h}\right)^{2} .
\end{aligned}
$$


The maximum principle conditions are:

$$
\begin{aligned}
0 & =\frac{\partial}{\partial A^{l}} H_{l i c}^{l}=\frac{\partial}{\partial A^{l}} G^{l}+\lambda_{1 t}^{l} \frac{\partial}{\partial A^{l}} g_{1}^{l}+\lambda_{2 t}^{l} \frac{\partial}{\partial A^{l}} g_{2}^{l}+\lambda_{3 t}^{l} \frac{\partial}{\partial A^{l}} g_{3}^{l} \\
0 & =\frac{\partial}{\partial p^{l}} H_{l i c}^{l}=\frac{\partial}{\partial p^{l}} G^{l}+\lambda_{1 t}^{l} \frac{\partial}{\partial p^{l}} g_{1}^{l}+\lambda_{2 t}^{l} \frac{\partial}{\partial p^{l}} g_{2}^{l}+\lambda_{3 t}^{l} \frac{\partial}{\partial p^{l}} g_{3}^{l} \\
\dot{N}_{t}^{h} & =\frac{\partial}{\partial \lambda_{1 h}^{l}} H_{l i c}^{l}=g_{1}^{l}\left(r_{t}^{h}, f_{t}^{h}, A_{t}^{h}, A_{t}^{l}, p_{t}^{h}, p_{t}^{l}, N_{t}^{h}, l_{t}, N_{t}^{l}, t\right) \\
\dot{l}_{t} & =\frac{\partial}{\partial \lambda_{2 h}^{l}} H_{l i c}^{l}=g_{2}^{l}\left(r_{t}^{h}, f_{t}^{h}, A_{t}^{h}, A_{t}^{l}, p_{t}^{h}, p_{t}^{l}, N_{t}^{h}, l_{t}, N_{t}^{l}, t\right) \\
\dot{N}_{t}^{l} & =\frac{\partial}{\partial \lambda_{3}^{l}} H_{l i c}^{l}=g_{3}^{l}\left(r_{t}^{h}, f_{t}^{h}, A_{t}^{h}, A_{t}^{l}, p_{t}^{h}, p_{t}^{l}, N_{t}^{h}, l_{t}, N_{t}^{l}, t\right) \\
\dot{\lambda}_{1 t}^{l} & =-\frac{\partial}{\partial N^{h}} H_{l i c}^{l}=-\frac{\partial}{\partial N^{h}} G^{l}-\lambda_{1 t}^{l} \frac{\partial}{\partial N^{h}} g_{1}^{l}-\lambda_{2 t}^{l} \frac{\partial}{\partial N^{h}} g_{2}^{l}-\lambda_{3 t}^{l} \frac{\partial}{\partial N^{h}} g_{3}^{l} \\
\dot{\lambda}_{t 2}^{l} & =-\frac{\partial}{\partial l^{h}} H_{l i c}^{l}=-\frac{\partial}{\partial l^{h}} G^{l}-\lambda_{1 t}^{l} \frac{\partial}{\partial l^{h}} g_{1}^{l}-\lambda_{2 t}^{l} \frac{\partial}{\partial l^{h}} g_{2}^{l}-\lambda_{3 t}^{l} \frac{\partial}{\partial l^{h}} g_{3}^{l} \\
\dot{\lambda}_{3 t}^{l} & =-\frac{\partial}{\partial N^{l}} H_{l i c}^{l}=-\frac{\partial}{\partial N^{l}} G^{l}-\lambda_{1 t}^{l} \frac{\partial}{\partial N^{l}} g_{1}^{l}-\lambda_{2 t}^{l} \frac{\partial}{\partial N^{l}} g_{2}^{l}-\lambda_{3 t}^{l} \frac{\partial}{\partial N^{l}} g_{3}^{l}
\end{aligned}
$$

and $N_{0}^{l}=N_{0}^{h}=l_{0}=0, \lambda_{t 1}^{l}, \lambda_{t 2}^{l}, \lambda_{t 3}^{l} \rightarrow 0$. From the first condition:

$$
\begin{aligned}
0= & -e^{-i t}+\lambda_{t 1}^{l} \frac{s}{A_{t}^{l}}\left(\left(a+u \frac{N_{t}^{h}}{M}+g \frac{N_{t}^{l}}{M}\right)\left(M-N_{t}^{h}-N_{t}^{l}\right)-k_{h} N_{t}^{h}\right) \\
& +\lambda_{t 3}^{l} \frac{\sigma}{A_{t}^{l}}\left(\left(\alpha+v \frac{N_{t}^{h}}{M}+\gamma \frac{N_{t}^{l}}{M}+\chi \frac{l_{t}}{L}\right)\left(M-N_{t}^{h}-N_{t}^{l}\right)-k_{l} N_{t}^{l}\right)
\end{aligned}
$$

and multiplying by $e^{i t} A_{t}^{l}$ we obtain the expression

$$
\begin{aligned}
A_{t}^{l}= & e^{i t}\left[\lambda_{1 t}^{l} s\left(a+u \frac{N_{t}^{h}}{M}+g \frac{N_{t}^{l}}{M}\right)+\lambda_{3 t}^{l} \sigma\left(\alpha+v \frac{N_{t}^{h}}{M}+\gamma \frac{N_{t}^{l}}{M}+\chi \frac{l_{t}}{L}\right)\right] \\
& \times\left(M-N_{t}^{h}-N_{t}^{l}\right)-k_{h} s e^{i t} \lambda_{1 t}^{l} N_{t}^{h}-k_{l} \sigma e^{i t} \lambda_{3 t}^{l} N_{t}^{l}
\end{aligned}
$$


The second condition leads to:

$$
\begin{aligned}
0= & e^{-i t} N_{t}^{l}-\lambda_{1 t}^{l} 2 d\left(e^{r t} \bar{p}-p_{t}^{l}\right)\left(\left(a+u \frac{N_{t}^{h}}{M}+g \frac{N_{t}^{l}}{M}\right)\left(M-N_{t}^{h}-N_{t}^{l}\right)-k_{h} N_{t}^{h}\right) \\
& +\lambda_{3 t}^{l} 2 \delta\left(e^{r t} \bar{p}-p_{t}^{l}\right)\left(\left(\alpha+v \frac{N_{t}^{h}}{M}+\gamma \frac{N_{t}^{l}}{M}+\chi \frac{l_{t}}{L}\right)\left(M-N_{t}^{h}-N_{t}^{l}\right)-k_{l} N_{t}^{l}\right)
\end{aligned}
$$

implying that

$$
\begin{aligned}
p_{t}^{l}= & e^{r t} \bar{p}+e^{-i t} N_{t}^{l} /\left(-\lambda_{1 t}^{l} 2 d\left(\left(a+u \frac{N_{t}^{h}}{M}+g \frac{N_{t}^{l}}{M}\right)\left(M-N_{t}^{h}-N_{t}^{l}\right)-k_{h} N_{t}^{h}\right)\right. \\
& \left.+\lambda_{3 t}^{l} 2 \delta\left(\left(\alpha+v \frac{N_{t}^{h}}{M}+\gamma \frac{N_{t}^{l}}{M}+\chi \frac{l_{t}}{L}\right)\left(M-N_{t}^{h}-N_{t}^{l}\right)-k_{l} N_{t}^{l}\right)\right)
\end{aligned}
$$

From the third, fourth and fifth conditions we have the equations (2), (3), (4). Finally, we obtain the equations for $\dot{\lambda}_{1 t}^{l}, \dot{\lambda}_{2 t}^{l}$ and $\dot{\lambda}_{3 t}^{l}$.

B) Consider the decisions of the IPR holder (licensor). Denote by $\lambda_{1 t}^{h}, \lambda_{2 t}^{h}$, and $\lambda_{3 t}^{h}$ the multipliers associated to $\dot{N}_{t}^{h}, \dot{l}_{t}, \dot{N}_{t}^{l}$, respectively. The HJB equation of the licensor's problem is a function $H_{\text {lic }}^{h}=H_{\text {lic }}^{h}\left(r_{t}^{h}, f_{t}^{h}, A_{t}^{h}, A_{t}^{l}, p_{t}^{h}, p_{t}^{l}, N_{t}^{h}, l_{t}, N_{t}^{l}, t\right)$ defined as:

$$
\begin{aligned}
H_{l i c}^{h} & =G^{h}+\lambda_{1 t}^{h} g_{1}^{h}+\lambda_{2 t}^{h} g_{2}^{h}+\lambda_{3 t}^{h} g_{l h} \\
G^{h} & =e^{-i t}\left(\left(p_{t}^{h}-c_{t}^{h}\right) N_{t}^{h}-A_{t}^{h}+f_{t}^{h} l_{t}+r_{t}^{h} N_{t}^{l}\right) \\
g_{1}^{h} & =\left(\left(a+u \frac{N_{t}^{h}}{M}+g \frac{N_{t}^{l}}{M}\right)\left(M-N_{t}^{h}-N_{t}^{l}\right)-k_{h} N_{t}^{h}\right) W_{t}^{h}\left(A_{t}^{h}, A_{t}^{l}, p_{t}^{h}, p_{t}^{l}\right) \\
g_{2}^{h} & =\left(\left(z_{1}+z_{2} \frac{l_{t}}{L}+z_{3} \frac{N_{t}^{l}}{M}\right)\left(L-l_{t}\right)-z_{4} l_{t}\right) L_{t}\left(f_{t}^{h}, r_{t}^{h}\right), \\
g_{3}^{h} & =\left(\left(\alpha+v \frac{N_{t}^{h}}{M}+\gamma \frac{N_{t}^{l}}{M}+\chi \frac{l_{t}}{L}\right)\left(M-N_{t}^{h}-N_{t}^{l}\right)-k_{l} N_{t}^{l}\right) W_{t}^{l}\left(A_{t}^{h}, A_{t}^{l}, p_{t}^{h}, p_{t}^{l}\right) .
\end{aligned}
$$


The maximum principle conditions are:

$$
\begin{aligned}
0 & =\frac{\partial}{\partial A^{h}} H_{l i c}^{h}=\frac{\partial}{\partial A^{h}} G^{h}+\lambda_{1 t}^{h} \frac{\partial}{\partial A^{h}} g_{1}^{h}+\lambda_{2 t}^{h} \frac{\partial}{\partial A^{h}} g_{2}^{h}+\lambda_{3 t}^{h} \frac{\partial}{\partial A^{h}} g_{3}^{h} \\
0 & =\frac{\partial}{\partial p^{h}} H_{l i c}^{h}=\frac{\partial}{\partial p^{h}} G^{h}+\lambda_{1 t}^{h} \frac{\partial}{\partial p^{h}} g_{1}^{h}+\lambda_{2 t}^{h} \frac{\partial}{\partial p^{h}} g_{2}^{h}+\lambda_{3 t}^{h} \frac{\partial}{\partial p^{h}} g_{2}^{h} \\
0 & =\frac{\partial}{\partial f^{h}} H_{l i c}^{h}=\frac{\partial}{\partial f^{h}} G^{h}+\lambda_{1 t}^{h} \frac{\partial}{\partial f^{h}} g_{1}^{h}+\lambda_{2 t}^{h} \frac{\partial}{\partial f^{h}} g_{2}^{h}+\lambda_{3 t}^{h} \frac{\partial}{\partial f^{h}} g_{3}^{h} \\
0 & =\frac{\partial}{\partial r^{h}} H_{l i c}^{h}=\frac{\partial}{\partial r^{h}} G^{h}+\lambda_{1 t}^{h} \frac{\partial}{\partial r^{h}} g_{1}^{h}+\lambda_{2 t}^{h} \frac{\partial}{\partial r^{h}} g_{2 t}^{h}+\lambda_{3 t}^{h} \frac{\partial}{\partial r^{h}} g_{3}^{h} \\
\dot{N}_{t}^{h} & =\frac{\partial}{\partial \lambda_{1}^{h}} H_{l i c}^{h}=g_{1}^{h}\left(t, r_{t}^{h}, f_{t}^{h}, p_{t}^{h}, A_{t}^{h}, N_{t}^{h}\right) \\
\dot{l}_{t} & =\frac{\partial}{\partial \lambda_{2}^{h}} H_{l i c}^{h}=g_{2}^{h}\left(t, r_{t}^{h}, f_{t}^{h}, p_{t}^{h}, A_{t}^{h}, N_{t}^{h}\right) \\
\dot{N}_{t}^{l} & =\frac{\partial}{\partial \lambda_{3}^{h}} H_{l i c}^{h}=g_{3}^{h}\left(t, p_{t}^{l}, A_{t}^{l}, N_{t}^{l}\right) \\
\dot{\lambda}_{1}^{h} & =-\frac{\partial}{\partial N^{h}} H_{l i c}^{h}=-\frac{\partial}{\partial N^{h}} G^{h}-\lambda_{1 t}^{h} \frac{\partial}{\partial N^{h}} g_{1}^{h}-\lambda_{2 t}^{h} \frac{\partial}{\partial N^{h}} g_{2}^{h}-\lambda_{3 t}^{h} \frac{\partial}{\partial N^{h}} g_{3}^{h} \\
\dot{\lambda}_{2}^{h} & =-\frac{\partial}{\partial l^{h}} H_{l i c}^{h}=-\frac{\partial}{\partial l^{h}} G^{h}-\lambda_{1 t}^{h} \frac{\partial}{\partial l^{h}} g_{1}^{h}-\lambda_{2 t}^{h} \frac{\partial}{\partial l^{h}} g_{2}^{h}-\lambda_{3 t}^{h} \frac{\partial}{\partial l^{h}} g_{3}^{h} \\
\dot{\lambda}_{3}^{h} & =-\frac{\partial}{\partial N^{l}} H_{l i c}^{h}=-\frac{\partial}{\partial N^{l}} G^{h}-\lambda_{1 t}^{h} \frac{\partial}{\partial N^{l}} g_{1}^{h}-\lambda_{2 t}^{h} \frac{\partial}{\partial N^{l}} g_{2 t}^{h}-\lambda_{3}^{h} \frac{\partial}{\partial N^{l}} g_{3}^{h}
\end{aligned}
$$

and $N_{0}^{h}=N_{0}^{l}=l_{0}=0, \lim _{t \rightarrow \infty} \lambda_{1}^{h} N_{t}^{h}=0, \lim _{t \rightarrow \infty} \lambda_{2}^{h} l_{t}=0, \lim _{t \rightarrow \infty} \lambda_{3}^{h} N_{t}^{l}=0$.

From the first condition:

$$
\begin{aligned}
0= & -e^{-i t}+\lambda_{1 t}^{h}\left(\left(a+u \frac{N_{t}^{h}}{M}+g \frac{N_{t}^{l}}{M}\right)\left(M-N_{t}^{h}-N_{t}^{l}\right)-k_{h} N_{t}^{h}\right) \frac{b}{A_{t}^{h}} \\
& +\lambda_{3 t}^{h}\left(\left(\alpha+v \frac{N_{t}^{h}}{M}+\gamma \frac{N_{t}^{l}}{M}+\chi \frac{l_{t}}{L}\right)\left(M-N_{t}^{h}-N_{t}^{l}\right)-k_{l} N_{t}^{l}\right) \frac{\beta}{A_{t}^{h}} \\
\Rightarrow & A_{t}^{h}=e^{i t}\left[b \lambda_{1 t}^{h}\left(a+u \frac{N_{t}^{h}}{M}+g \frac{N_{t}^{l}}{M}\right)+\lambda_{3 t}^{h} \beta\left(\alpha+v \frac{N_{t}^{h}}{M}+\gamma \frac{N_{t}^{l}}{M}+\chi \frac{l_{t}}{L}\right)\right] \\
& \times\left(M-N_{t}^{h}-N_{t}^{l}\right)-k_{h} b e^{i t} \lambda_{1 t}^{h} N_{t}^{h}-k_{l} \beta e^{i t} \lambda_{3 t}^{h} N_{t}^{l} .
\end{aligned}
$$


The second condition leads to:

$$
\begin{aligned}
0= & e^{-i t} N_{t}^{h}+\lambda_{1 t}^{h} 2 m\left(e^{r t} \bar{p}-p_{t}^{h}\right)\left[\left(a+u \frac{N_{t}^{h}}{M}+g \frac{N_{t}^{l}}{M}\right)\left(M-N_{t}^{h}-N_{t}^{l}\right)-k_{h} N_{t}^{h}\right] \\
& -\lambda_{3 t}^{h} 2 \mu\left(e^{r t} \bar{p}-p_{t}^{h}\right)\left[\left(\alpha+v \frac{N_{t}^{h}}{M}+\gamma \frac{N_{t}^{l}}{M}+\chi \frac{l_{t}}{L}\right)\left(M-N_{t}^{h}-N_{t}^{l}\right)-k_{l} N_{t}^{l}\right]
\end{aligned}
$$

and therefore

$$
\begin{aligned}
p_{t}^{h}= & e^{r t} \bar{p}+e^{-i t} N_{t}^{h} /\left(\lambda_{1 t}^{h} 2 m\left[\left(a+u \frac{N_{t}^{h}}{M}+g \frac{N_{t}^{l}}{M}\right)\left(M-N_{t}^{h}-N_{t}^{l}\right)-k_{h} N_{t}^{h}\right]\right. \\
& \left.-\lambda_{3 t}^{h} 2 \mu\left[\left(\alpha+v \frac{N_{t}^{h}}{M}+\gamma \frac{N_{t}^{l}}{M}+\chi \frac{l_{t}}{L}\right)\left(M-N_{t}^{h}-N_{t}^{l}\right)-k_{l} N_{t}^{l}\right]\right)
\end{aligned}
$$

From the third condition:

$$
\begin{aligned}
0 & =e^{-i t} l_{t}+\lambda_{2 t}^{h} 2 z_{6}\left(e^{r t} \bar{f}-f_{t}^{h}\right)\left[\left(z_{1}+z_{2} \frac{l_{t}}{L}+z_{3} \frac{N_{t}^{l}}{M}\right)\left(L-l_{t}\right)-z_{4} l_{t}\right] \\
f_{t}^{h} & =e^{r t} \bar{f}+\frac{e^{-i t} l_{t}}{\lambda_{2 t}^{h} 2 z_{5}\left[\left(z_{1}+z_{2} \frac{l_{t}}{L}+z_{3} \frac{N_{t}^{l}}{M}\right)\left(L-l_{t}\right)-z_{4} l_{t}\right]}
\end{aligned}
$$

From the fourth equation we get:

$$
\begin{aligned}
0 & =e^{-i t} N_{t}^{l}+\lambda_{2 t}^{h} 2 z_{7}\left(e^{r t} \bar{r}-r_{t}^{h}\right)\left[\left(z_{1}+z_{2} \frac{l_{t}}{L}+z_{3} \frac{N_{t}^{l}}{M}\right)\left(L-l_{t}\right)-z_{4} l_{t}\right] \\
r_{t}^{h} & =e^{r t} \bar{r}+\frac{e^{-i t} N_{t}^{l}}{\lambda_{2 t}^{h} 2 z_{6}\left[\left(z_{1}+z_{2} \frac{l_{t}}{L}+z_{3} \frac{N_{t}^{l}}{M}\right)\left(L-l_{t}\right)-z_{4} l_{t}\right]}
\end{aligned}
$$

Also, the equations (2), (3), (4) are satisfied. Finally, we obtain the equations for $\dot{\lambda}_{1 t}^{h}, \dot{\lambda}_{2 t}^{h}, \dot{\lambda}_{3 t}^{h}$.

\section{Proof. (Proposition 3)}

First, consider the decisions of the IPR holder. We define the HJB equation

$$
H_{\text {piracy }}^{h}=H_{\text {piracy }}^{h}\left(A_{t}^{h}, A_{t}^{c}, p_{t}^{h}, p_{t}^{c}, N_{t}^{h}, N_{t}^{c}, l_{t}^{c}, t\right)
$$


as follows:

$$
\begin{aligned}
H_{\text {piracy }}^{h} & =G^{h}\left(p_{t}^{h}, A_{t}^{h}, N_{t}^{h}, t\right)+\lambda_{1 t}^{h} g_{1}\left(p_{t}^{h}, A_{t}^{h}, N_{t}^{h}, t\right)+\lambda_{2 t}^{h} g_{2}\left(l_{t}^{c}, N_{t}^{c}\right)+\lambda_{3 t}^{h} g_{3}\left(p_{t}^{h}, A_{t}^{h}, N_{t}^{h}, t\right) \\
G^{h}\left(p_{t}^{h}, A_{t}^{h}, N_{t}^{h}, t\right) & =e^{-i t}\left(\left(p_{t}^{h}-c_{t}^{h}\right) N_{t}^{h}-A_{t}^{h}\right) \\
g_{1} & =\left[\left(a+u \frac{N_{t}^{h}}{M^{h}}+g \frac{N_{t}^{c}}{M^{c}}\right)\left(M^{h}-N_{t}^{h}\right)-k_{h} N_{t}^{h}\right] W_{t}^{h}\left(A_{t}^{h}, A_{t}^{c}, p_{t}^{h}, p_{t}^{c}\right) \\
g_{2} & =\left[\left(z_{1}+z_{2} \frac{l_{t}^{c}}{L}+z_{3} \frac{N_{t}^{c}}{M^{c}}\right)\left(L-l_{t}^{c}\right)-z_{4} l_{t}^{c}\right] \\
g_{3} & =\left[\left(\alpha+v \frac{N_{t}^{h}}{M^{h}}+\gamma \frac{N_{t}^{c}}{M^{c}}+\chi \frac{l_{t}^{c}}{L}\right)\left(M^{c}-N_{t}^{c}\right)-k_{c} N_{t}^{c}\right] W_{t}^{l}\left(A_{t}^{h}, A_{t}^{c}, p_{t}^{h}, p_{t}^{c}\right)
\end{aligned}
$$

The maximum principle conditions are:

$$
\begin{aligned}
0 & =\frac{\partial}{\partial A^{h}} H_{\text {piracy }}^{h}=\frac{\partial}{\partial A^{h}} G_{t}^{h}+\lambda_{1 t}^{h} \frac{\partial}{\partial A^{h}} g_{1}+\lambda_{2 t}^{h} \frac{\partial}{\partial A^{h}} g_{2}+\lambda_{3 t}^{h} \frac{\partial}{\partial A^{h}} g_{3}, \\
0 & =\frac{\partial}{\partial p^{h}} H_{\text {piracy }}^{h}=\frac{\partial}{\partial p^{h}} G_{t}^{h}+\lambda_{1 t}^{h} \frac{\partial}{\partial p^{h}} g_{1}+\lambda_{2 t}^{h} \frac{\partial}{\partial p^{h}} g_{2}+\lambda_{3 t}^{h} \frac{\partial}{\partial p^{h}} g_{3}, \\
\dot{N}_{t}^{h} & =\frac{\partial}{\partial \lambda_{1}^{h}} H_{\text {piracy }}^{h}=g_{1}\left(A_{t}^{h}, A_{t}^{c}, p_{t}^{h}, p_{t}^{c}, N_{t}^{h}, N_{t}^{c}, t\right) \\
\dot{l}_{t}^{c} & =\frac{\partial}{\partial \lambda_{2}^{h}} H_{\text {piracy }}^{h}=g_{2}\left(l_{t}^{c}, N_{t}^{c}, t\right) \\
\dot{N}_{t}^{c} & =\frac{\partial}{\partial \lambda_{3}^{h}} H_{\text {piracy }}^{h}=g_{3}\left(A_{t}^{h}, A_{t}^{c}, p_{t}^{h}, p_{t}^{c}, N_{t}^{h}, N_{t}^{c}, t\right) \\
\dot{\lambda}_{1 t}^{h} & =-\frac{\partial}{\partial N^{h}} H_{\text {piracy }}^{h}=-\frac{\partial}{\partial N^{h}} G_{t}^{h}-\lambda_{1 t}^{h} \frac{\partial}{\partial N^{h}} g_{1}-\lambda_{2 t}^{h} \frac{\partial}{\partial N^{h}} g_{2}-\lambda_{3 t}^{h} \frac{\partial}{\partial N^{h}} g_{3} \\
\dot{\lambda}_{2 t}^{h} & =-\frac{\partial}{\partial l^{c}} H_{\text {piracy }}^{h}=-\frac{\partial}{\partial l^{c}} G_{t}^{h}-\lambda_{1 t}^{h} \frac{\partial}{\partial l^{c}} g_{1}-\lambda_{2 t}^{h} \frac{\partial}{\partial l^{c}} g_{2}-\lambda_{3 t}^{h} \frac{\partial}{\partial l^{c}} g_{3} \\
\dot{\lambda}_{3 t}^{h} & =-\frac{\partial}{\partial N^{c}} H_{\text {piracy }}^{h}=-\frac{\partial}{\partial N^{c}} G_{t}^{h}-\lambda_{1 t}^{h} \frac{\partial}{\partial N^{c}} g_{1}-\lambda_{2 t}^{h} \frac{\partial}{\partial N^{c}} g_{2}-\lambda_{3 t}^{h} \frac{\partial}{\partial N^{c}} g_{3}
\end{aligned}
$$


with $N_{0}^{h}=0, N_{0}^{c}=0, l_{0}=0, \lambda_{1 t}^{h} \rightarrow 0, \lambda_{2 t}^{h} \rightarrow 0, \lambda_{3 t}^{h} \rightarrow 0$. From the first condition:

$$
\begin{aligned}
0= & -e^{-i t}+\lambda_{1 t}^{h}\left[\left(a+u \frac{N_{t}^{h}}{M^{h}}+g \frac{N_{t}^{c}}{M^{c}}\right)\left(M^{h}-N_{t}^{h}\right)-k_{h} N_{t}^{h}\right] \frac{b}{A_{t}^{h}} \\
& +\lambda_{3 t}^{h}\left[\left(\alpha+v \frac{N_{t}^{h}}{M^{h}}+\gamma \frac{N_{t}^{c}}{M^{c}}+\chi \frac{l_{t}^{c}}{L}\right)\left(M^{c}-N_{t}^{c}\right)-k_{c} N_{t}^{c}\right] \frac{\beta}{A_{t}^{h}} \\
\Rightarrow \quad & A_{t}^{h}=\lambda_{1 t}^{h} e^{i t}\left[\left(a+u \frac{N_{t}^{h}}{M^{h}}+g \frac{N_{t}^{c}}{M^{c}}\right)\left(M^{h}-N_{t}^{h}\right)-k_{h} N_{t}^{h}\right] b \\
& +\lambda_{3 t}^{h} e^{i t}\left[\left(\alpha+v \frac{N_{t}^{h}}{M^{h}}+\gamma \frac{N_{t}^{c}}{M^{c}}+\chi \frac{l_{t}^{c}}{L}\right)\left(M^{c}-N_{t}^{c}\right)-k_{c} N_{t}^{c}\right] \beta
\end{aligned}
$$

The second condition leads to:

$$
\begin{aligned}
0= & e^{-i t} N_{t}^{h}+\lambda_{1 t}^{h} 2 m\left(e^{r t} \bar{p}-p_{t}^{h}\right)\left[\left(a+u \frac{N_{t}^{h}}{M^{h}}+g \frac{N_{t}^{c}}{M^{c}}\right)\left(M^{h}-N_{t}^{h}\right)-k_{h} N_{t}^{h}\right]- \\
& \lambda_{3 t}^{h} 2 \mu\left(e^{r t} \bar{p}-p_{t}^{h}\right)\left[\left(\alpha+v \frac{N_{t}^{h}}{M^{h}}+\gamma \frac{N_{t}^{c}}{M^{c}}+\chi \frac{l_{t}^{c}}{L}\right)\left(M^{c}-N_{t}^{c}\right)-k_{c} N_{t}^{c}\right] \\
p_{t}^{h}= & e^{r t} \bar{p}+e^{-i t} N_{t}^{h} /\left(\lambda_{1 t}^{h} 2 m\left[\left(a+u \frac{N_{t}^{h}}{M^{h}}+g \frac{N_{t}^{c}}{M^{c}}\right)\left(M^{h}-N_{t}^{h}\right)-k_{h} N_{t}^{h}\right]\right. \\
& \left.-\lambda_{3 t}^{h} 2 \mu\left[\left(\alpha+v \frac{N_{t}^{h}}{M^{h}}+\gamma \frac{N_{t}^{c}}{M^{c}}+\chi \frac{l_{t}^{c}}{L}\right)\left(M^{c}-N_{t}^{c}\right)-k_{c} N_{t}^{c}\right]\right)
\end{aligned}
$$

From the third, fourth, and fifth conditions we have the equations (8), (9), (10). The sixth, seventh, and eighth conditions lead to:

$$
\begin{aligned}
\dot{\lambda}_{1 t}^{h}= & -e^{-i t}\left(p_{t}^{h}-c_{t}^{h}\right)-\lambda_{1 t}^{h}\left[u \frac{1}{M^{h}}\left(M^{h}-N_{t}^{h}\right)-\left(a+u \frac{N_{t}^{h}}{M^{h}}+g \frac{N_{t}^{c}}{M^{c}}\right)-k_{h}\right] W_{t}^{h}\left(A_{t}^{h}, A_{t}^{c}, p_{t}^{h}, p_{t}^{c}\right) \\
& -\lambda_{3}^{h} v \frac{1}{M^{h}}\left(M^{c}-N_{t}^{c}\right) W_{t}^{c}\left(A_{t}^{h}, A_{t}^{c}, p_{t}^{h}, p_{t}^{c}\right) \\
\dot{\lambda}_{2 t}^{h}= & -\lambda_{2}^{h}\left[z_{2} \frac{1}{L}\left(L-l_{t}^{c}\right)-\left(z_{1}+z_{2} \frac{l_{t}^{c}}{L}+z_{3} \frac{N_{t}^{c}}{M^{c}}\right)\left(L-l_{t}^{c}\right)-z_{4}\right]-\lambda_{3}^{h} \chi \frac{1}{L}\left(M^{c}-N_{t}^{c}\right) W_{t}^{c}\left(A_{t}^{h}, A_{t}^{c}, p_{t}^{h}, p_{t}^{c}\right) \\
\dot{\lambda}_{3 t}^{h}= & -\lambda_{1}^{h} g \frac{1}{M^{c}}\left(M^{h}-N_{t}^{h}\right) W_{t}^{h}\left(A_{t}^{h}, A_{t}^{c}, p_{t}^{h}, p_{t}^{c}\right)-\lambda_{2}^{h} z_{3} \frac{1}{M^{c}}\left(L-l_{t}^{c}\right) \\
& -\lambda_{3}^{h}\left[\gamma \frac{1}{M^{c}}\left(M^{c}-N_{t}^{c}\right)-\left(\alpha+v \frac{N_{t}^{h}}{M^{h}}+\gamma \frac{N_{t}^{c}}{M^{c}}+\chi \frac{l_{t}^{c}}{L}\right)-k_{c}\right] W_{t}^{c}\left(A_{t}^{h}, A_{t}^{c}, p_{t}^{h}, p_{t}^{c}\right)
\end{aligned}
$$


Next, consider the decisions of the pirates. We define the HJB equation

$$
H_{\text {piracy }}^{c}=H_{\text {piracy }}^{c}\left(A_{t}^{h}, A_{t}^{c}, p_{t}^{h}, p_{t}^{c}, N_{t}^{h}, N_{t}^{c}, t\right)
$$

as follows:

$$
\begin{aligned}
H_{\text {piracy }}^{c} & =G^{c}\left(p_{t}^{c}, A_{t}^{c}, N_{t}^{c}, t\right)+\lambda_{1}^{c} g_{1}+\lambda_{2}^{c} g_{2}+\lambda_{3}^{c} g_{3} \\
G^{c} & =e^{-i t}\left(\left(p_{t}^{c}-c_{t}^{c}\right) N_{t}^{c}-A_{t}^{c}\right) \\
g_{1} & =\left[\left(a+u \frac{N_{t}^{h}}{M^{h}}+g \frac{N_{t}^{c}}{M^{c}}\right)\left(M^{h}-N_{t}^{h}\right)-k_{h} N_{t}^{h}\right] W_{t}^{h}\left(A_{t}^{h}, A_{t}^{c}, p_{t}^{h}, p_{t}^{c}\right) \\
g_{2} & =\left[\left(z_{1}+z_{2} \frac{l_{t}^{c}}{L}+z_{3} \frac{N_{t}^{c}}{M^{c}}\right)\left(L-l_{t}^{c}\right)-z_{4} l_{t}^{c}\right] \\
g_{3} & =\left[\left(\alpha+v \frac{N_{t}^{h}}{M^{h}}+\gamma \frac{N_{t}^{c}}{M^{c}}+\chi \frac{l_{t}^{c}}{L}\right)\left(M^{c}-N_{t}^{c}\right)-k_{c} N_{t}^{c}\right] W_{t}^{c}\left(A_{t}^{h}, A_{t}^{c}, p_{t}^{h}, p_{t}^{c}\right)
\end{aligned}
$$

The maximum principle conditions are:

$$
\begin{aligned}
0 & =\frac{\partial}{\partial A^{c}} H_{\text {piracy }}^{c}=\frac{\partial}{\partial A^{c}} G_{t}^{c}+\lambda_{1}^{c} \frac{\partial}{\partial A^{c}} g_{1}+\lambda_{2}^{c} \frac{\partial}{\partial A^{c}} g_{2}+\lambda_{3}^{c} \frac{\partial}{\partial A^{c}} g_{3}, \\
0 & =\frac{\partial}{\partial p^{c}} H_{\text {piracy }}^{c}=\frac{\partial}{\partial p^{c}} G_{t}^{c}+\lambda_{1}^{c} \frac{\partial}{\partial p^{c}} g_{1}+\lambda_{2}^{c} \frac{\partial}{\partial p^{c}} g_{2}+\lambda_{3}^{c} \frac{\partial}{\partial p^{c}} g_{3}, \\
\dot{N}_{t}^{h} & =\frac{\partial}{\partial \lambda_{1}^{c}} H_{\text {piracy }}^{c}=g_{1}\left(A_{t}^{h}, A_{t}^{c}, p_{t}^{h}, p_{t}^{c}, N_{t}^{h}, N_{t}^{c}, t\right), \\
\dot{l}_{t}^{c} & =\frac{\partial}{\partial \lambda_{2}^{c}} H_{\text {piracy }}^{c}=g_{2}\left(l_{t}^{c}, N_{t}^{c}, t\right) \\
\dot{N}_{t}^{c} & =\frac{\partial}{\partial \lambda_{3}^{c}} H_{\text {piracy }}^{c}=g_{3}\left(A_{t}^{h}, A_{t}^{c}, p_{t}^{h}, p_{t}^{c}, N_{t}^{h}, N_{t}^{c}, l_{t}^{c}, t\right) \\
\dot{\lambda}_{1}^{c} & =-\frac{\partial}{\partial N^{h}} H_{\text {piracy }}^{c}=-\frac{\partial}{\partial N^{h}} G_{t}^{c}-\lambda_{1}^{c} \frac{\partial}{\partial N^{h}} g_{1}-\lambda_{2}^{c} \frac{\partial}{\partial N^{h}} g_{2}-\lambda_{3}^{c} \frac{\partial}{\partial N^{h}} g_{3} \\
\dot{\lambda}_{2}^{c} & =-\frac{\partial}{\partial l^{c}} H_{\text {piracy }}^{c}=-\frac{\partial}{\partial l^{c}} G_{t}^{c}-\lambda_{1}^{c} \frac{\partial}{\partial l^{c}} g_{1}-\lambda_{2}^{c} \frac{\partial}{\partial l^{c}} g_{2}-\lambda_{3}^{c} \frac{\partial}{\partial l^{c}} g_{3} \\
\dot{\lambda}_{3}^{c} & =-\frac{\partial}{\partial N^{c}} H_{\text {piracy }}^{c}=-\frac{\partial}{\partial N^{c}} G_{t}^{c}-\lambda_{1}^{c} \frac{\partial}{\partial N^{c}} g_{1}-\lambda_{2}^{c} \frac{\partial}{\partial N^{c}} g_{2}-\lambda_{3}^{c} \frac{\partial}{\partial N^{c}} g_{3}
\end{aligned}
$$


with $N_{0}^{h}=0, N_{0}^{c}=0, l_{0}=0, \lambda_{1}^{c} \rightarrow 0, \lambda_{2}^{c} \rightarrow 0, \lambda_{3}^{c} \rightarrow 0$. From the first condition:

$$
\begin{aligned}
0= & -e^{-i t}+\lambda_{1 t}^{c}\left[\left(a+u \frac{N_{t}^{h}}{M^{h}}+g \frac{N_{t}^{c}}{M^{c}}\right)\left(M^{h}-N_{t}^{h}\right)-k_{h} N_{t}^{h}\right] \frac{s}{A_{t}^{c}} \\
& +\lambda_{3 t}^{c}\left[\left(\alpha+v \frac{N_{t}^{h}}{M^{h}}+\gamma \frac{N_{t}^{c}}{M^{c}}+\chi \frac{l_{t}^{c}}{L}\right)\left(M^{c}-N_{t}^{c}\right)-k_{c} N_{t}^{c}\right] \frac{\sigma}{A_{t}^{c}} \\
\Rightarrow \quad & A_{t}^{c}=\lambda_{1 t}^{c} e^{i t}\left[\left(a+u \frac{N_{t}^{h}}{M^{h}}+g \frac{N_{t}^{c}}{M^{c}}\right)\left(M^{h}-N_{t}^{h}\right)-k_{h} N_{t}^{h}\right] s \\
& +\lambda_{3 t}^{c} e^{i t}\left[\left(\alpha+v \frac{N_{t}^{h}}{M^{h}}+\gamma \frac{N_{t}^{c}}{M^{c}}+\chi \frac{l_{t}^{c}}{L}\right)\left(M^{c}-N_{t}^{c}\right)-k_{c} N_{t}^{c}\right] \sigma
\end{aligned}
$$

The second condition leads to:

$$
\begin{aligned}
0= & e^{-i t} N_{t}^{c}-\lambda_{1 t}^{c} 2 d\left(e^{r t} \bar{p}^{c}-p_{t}^{c}\right)\left[\left(a+u \frac{N_{t}^{h}}{M^{h}}+g \frac{N_{t}^{c}}{M^{c}}\right)\left(M^{h}-N_{t}^{h}\right)-k_{h} N_{t}^{h}\right] \\
& +\lambda_{3 t}^{c} 2 \delta\left(e^{r t} \bar{p}^{c}-p_{t}^{c}\right)\left[\left(\alpha+v \frac{N_{t}^{h}}{M^{h}}+\gamma \frac{N_{t}^{c}}{M^{c}}+\chi \frac{l_{t}^{c}}{L}\right)\left(M^{c}-N_{t}^{c}\right)-k_{c} N_{t}^{c}\right] \\
p_{t}^{c}= & e^{r t} \bar{p}^{c}+e^{-i t} N_{t}^{c} /\left(-\lambda_{1 t}^{c} 2 d\left[\left(a+u \frac{N_{t}^{h}}{M^{h}}+g \frac{N_{t}^{c}}{M^{c}}\right)\left(M^{h}-N_{t}^{h}\right)-k_{h} N_{t}^{h}\right]\right. \\
& \left.+\lambda_{3 t}^{c} 2 \delta\left[\left(\alpha+v \frac{N_{t}^{h}}{M^{h}}+\gamma \frac{N_{t}^{c}}{M^{c}}+\chi \frac{l_{t}^{c}}{L}\right)\left(M^{c}-N_{t}^{c}\right)-k_{c} N_{t}^{c}\right]\right)
\end{aligned}
$$

From the third, fourth, and fifth conditions we have the equations (8), (9), (10). The sixth, seventh, and eighth conditions lead to the co-state equations for $\lambda_{1 t}^{c}, \lambda_{2 t}^{c}, \lambda_{3 t}^{c}$.

$$
\begin{aligned}
\dot{\lambda}_{1 t}^{c}= & -\lambda_{1 t}^{c}\left[u \frac{1}{M^{h}}\left(M^{h}-N_{t}^{h}\right)-\left(a+u \frac{N_{t}^{h}}{M^{h}}+g \frac{N_{t}^{c}}{M^{c}}\right)-k_{h}\right] W_{t}^{h}\left(A_{t}^{h}, A_{t}^{c}, p_{t}^{h}, p_{t}^{c}\right) \\
& -\lambda_{3 t}^{c} v \frac{1}{M^{h}}\left(M^{c}-N_{t}^{c}\right) W_{t}^{c}\left(A_{t}^{h}, A_{t}^{c}, p_{t}^{h}, p_{t}^{c}\right) \\
\dot{\lambda}_{2 t}^{c}= & -\lambda_{2 t}^{c}\left[z_{2} \frac{1}{L}\left(L-l_{t}^{c}\right)-\left(z_{1}+z_{2} \frac{l_{t}^{c}}{L}+z_{3} \frac{N_{t}^{c}}{M^{c}}\right)\left(L-l_{t}^{c}\right)-z_{4}\right]-\lambda_{3}^{c} \chi \frac{1}{L}\left(M^{c}-N_{t}^{c}\right) W_{t}^{c}\left(A_{t}^{h}, A_{t}^{c}, p_{t}^{h}, p_{t}^{c}\right) \\
\dot{\lambda}_{3 t}^{c}= & -e^{-i t}\left(p_{t}^{c}-c_{t}^{c}\right)-\lambda_{1 t}^{c} g \frac{1}{M^{c}}\left(M^{h}-N_{t}^{h}\right) W_{t}^{h}\left(A_{t}^{h}, A_{t}^{c}, p_{t}^{h}, p_{t}^{c}\right)-\lambda_{2 t}^{c} z_{3} \frac{1}{M^{c}}\left(L-l_{t}^{c}\right) \\
& -\lambda_{3 t}^{c}\left[\gamma \frac{1}{M^{c}}\left(M^{c}-N_{t}^{c}\right)-\left(\alpha+v \frac{N_{t}^{h}}{M^{h}}+\gamma \frac{N_{t}^{c}}{M^{c}}+\chi \frac{l_{t}^{c}}{L}\right)-k_{c}\right] W_{t}^{c}\left(A_{t}^{h}, A_{t}^{c}, p_{t}^{h}, p_{t}^{c}\right)
\end{aligned}
$$


